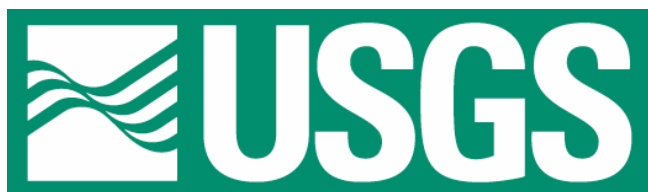

science for a changing world

In cooperation with Washington State Department of Natural Resources

\title{
Bathymetry, Substrate and Circulation in Westcott Bay, San Juan Islands, Washington
}

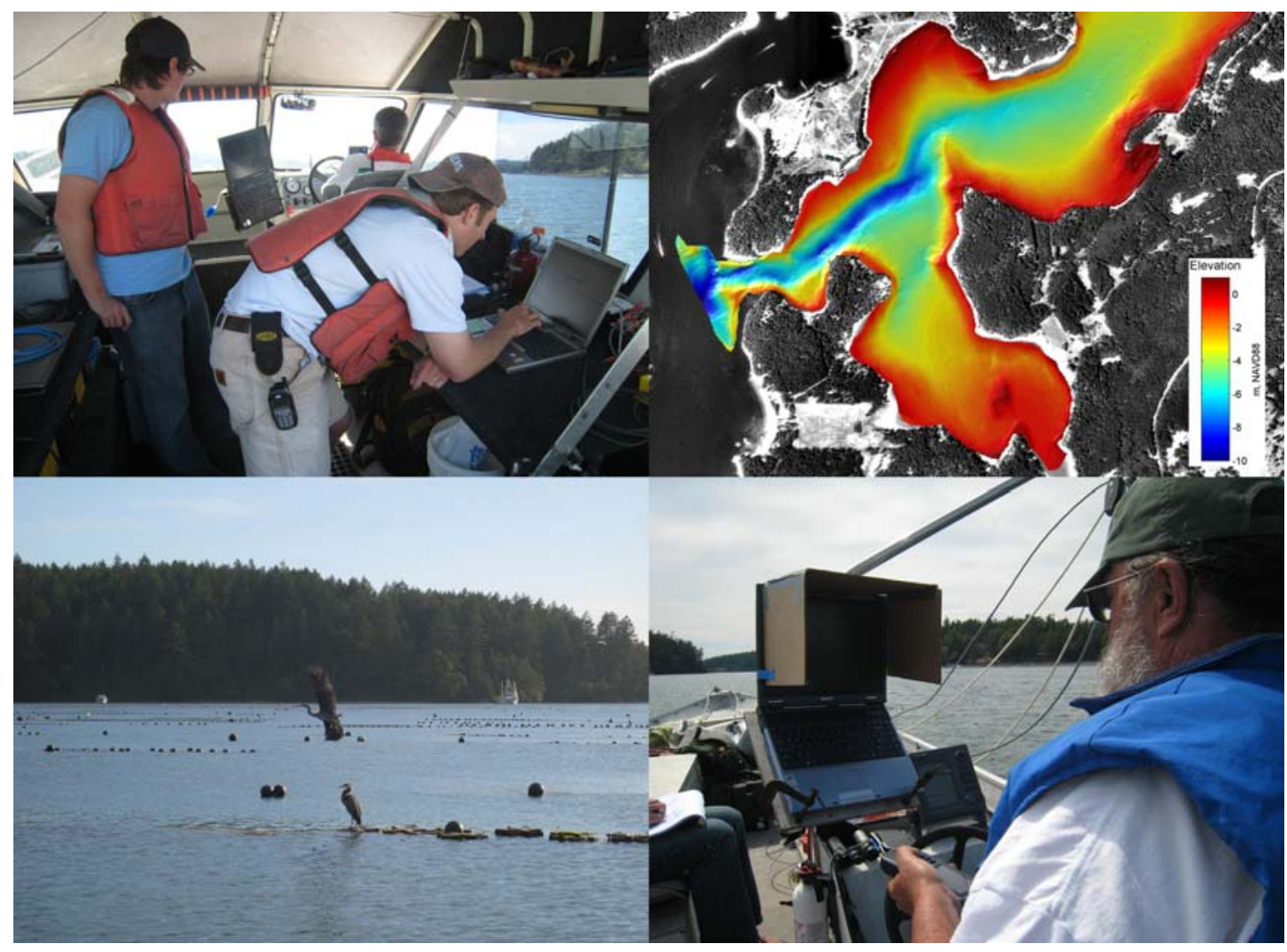

By Eric Grossman, Andrew Stevens, Chris Curran, Collin Smith, and Andrew Schwartz

Open-File Report 2007-1305

U.S. Department of the Interior

U.S. Geological Survey 


\title{
U.S. Department of the Interior \\ Dirk Kempthorne, Secretary
}

\section{U.S. Geological Survey \\ Mark Myers, Director}

\author{
U.S. Geological Survey, Reston, Virginia 2007
}

For product and ordering information:

World Wide Web: http://www.usgs.gov/pubprod

Telephone: 1-888-ASK-USGS

For more information on the USGS - the Federal source for science about the Earth, its natural and living resources, natural hazards, and the environment:

World Wide Web: http://www.usgs.gov

Telephone: 1-888-ASK-USGS

Suggested citation:

Grossman, EE, Stevens, A, Curran, C., Smith, C, and Schwartz, A. 2007, Bathymetry, substrate and circulation in Westcott Bay, San Juan Islands, Washington U.S. Geological Survey Open-File Report 2007-1305, pp. 42.

Available online at: http:pubs.usgs.gov/of/2007/1305/

Any use of trade, product, or firm names is for descriptive purposes only and does not imply endorsement by the U.S. Government.

Although this report is in the public domain, permission must be secured from the individual copyright owners to reproduce any copyrighted material contained within this report. 


\section{Contents}

Abstract

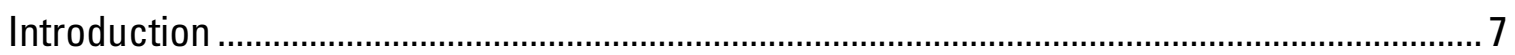

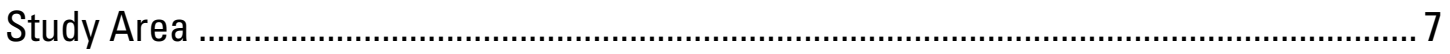

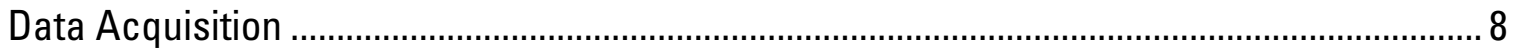

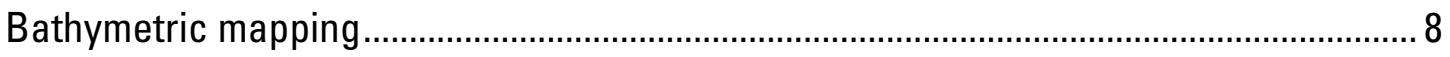

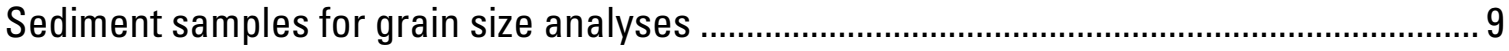

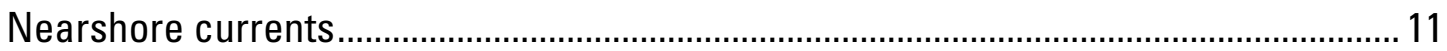

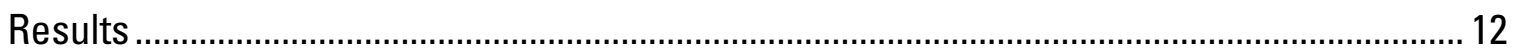

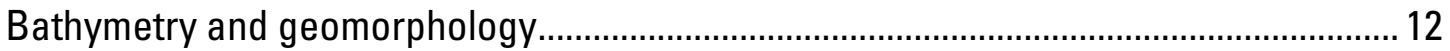

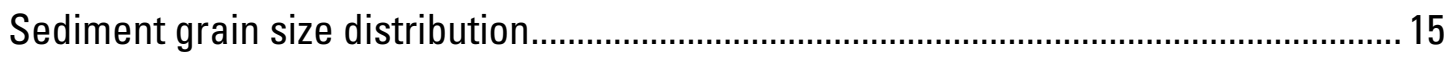

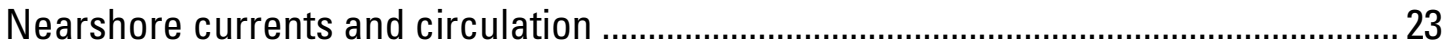

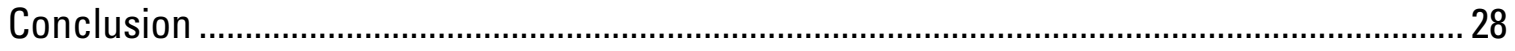

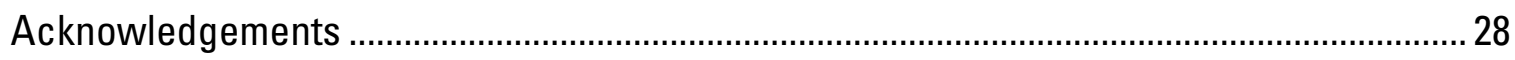

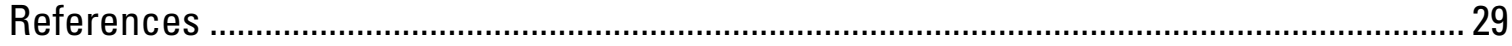

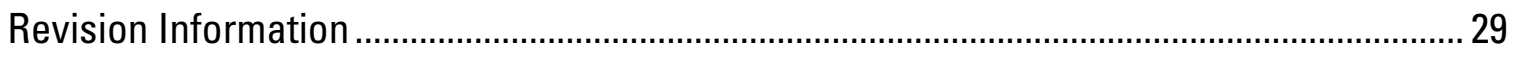

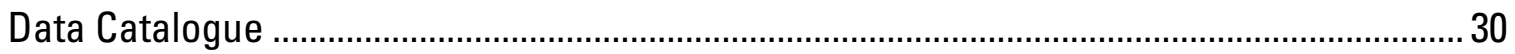

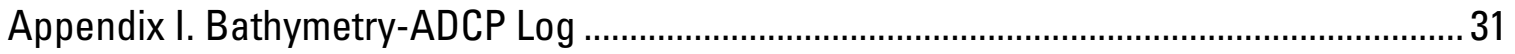

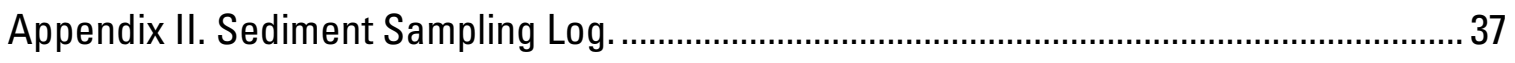

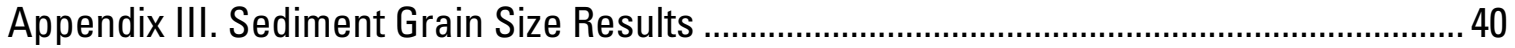




\section{Figures}

1. Location map showing Westc ott Bay and study area.......................................................

2. Map of survey track lines .......................................................................................... 8

3. Map showing sediment grab sample locations …………………………………….... 10

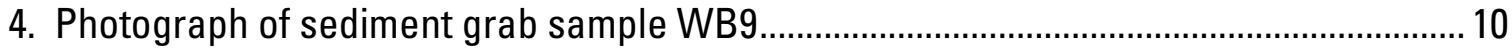

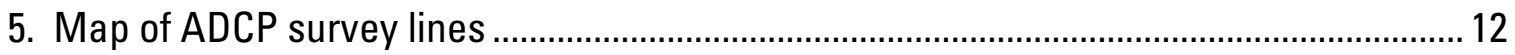

6. Surface map of Westcott Bay ......................................................................................... 13

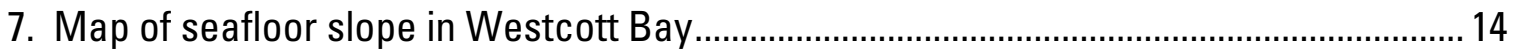

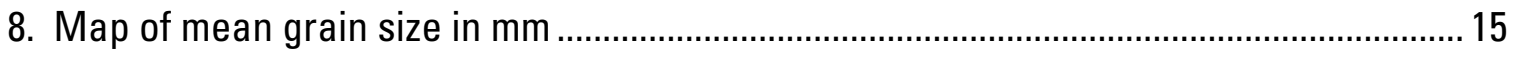

9. Map of mean grain size classified by classes (in $\mathrm{mm}$ ) ................................................... 16

10. Map of mean grain size in phi units ........................................................................... 17

11. Map of mean grain size classified by classes (in phi) ................................................... 18

12. Map of sediment sorting ......................................................................................... 19

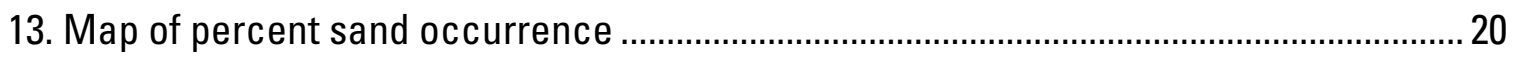

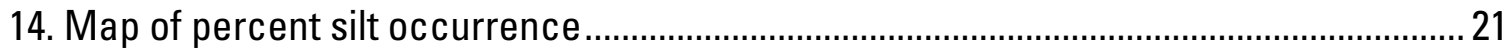

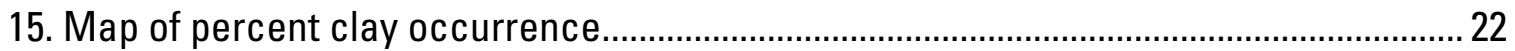

16. Map of depth-averaged current velocity during flooding tide of May 31, 2007 ...............23

17. Cross-sectional diagram of ADCP derived current velocity, current direction and backscatter during flooding tide of May 31, 2007.............................................. 24

18. Map of depth-averaged current velocity during ebbing tide of June 2, 2007 ..................25

19. Cross-sectional diagram of ADCP derived current velocity, current direction

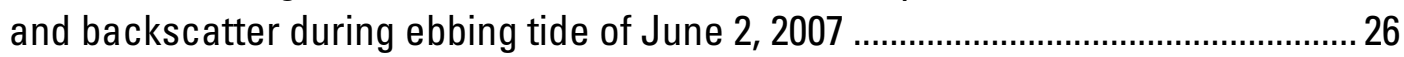

20. Map of depth-averaged currents over a 2- hour period on May 31, 2007 ....................... 27 


\section{Appendixes}

Appendix I. Bathymetry/ADCP Survey Log for USGS Cruise ID (B-6-07-PS)..........................31

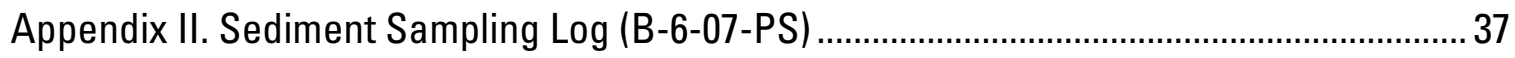

Appendix II. Grain size results. Size classes in percent. ....................................................... 40 


\title{
Bathymetry, Substrate, and Circulation in Westcott Bay, San Juan Islands, Washington
}

\author{
Eric E. Grossman', Andrew Stevens' ${ }^{2}$, Christopher Curran ${ }^{3}$, Collin Smith ${ }^{5}$, and Andrew \\ Schwartz ${ }^{5}$ \\ ${ }^{1}$ U.S .Geological Survey, Pacific Science Center, Santa Cruz, CA \\ ${ }^{2}$ U.S. Geological Survey, Menlo Park, CA \\ ${ }^{3}$ U.S. Geological Survey, Washington Water Science Center, Tacoma, WA \\ ${ }^{3}$ U.S. Geological Survey, Western Fisheries Research Center, Cook, WA \\ ${ }^{3}$ Washington State Department of Ecology, Olympia, WA
}

\begin{abstract}
Nearshore bathymetry, substrate type, and circulation patterns in Westcott Bay, San Juan Islands, Washington, were mapped using two acoustic sonar systems, video and direct sampling of seafloor sediments. The goal of the project was to characterize nearshore habitat and conditions influencing eelgrass (Z. marina) where extensive loss has occurred since 1995. A principal hypothesis for the loss of eelgrass is a recent decrease in light availability for eelgrass growth due to increase in turbidity associated with either an increase in fine sedimentation or biological productivity within the bay. To explore sources for this fine sediment and turbidity, a dual-frequency Biosonics sonar operating at 200 and $430 \mathrm{kHz}$ was used to map seafloor depth, morphology and vegetation along 69 linear kilometers of the bay. The higher frequency $430 \mathrm{kHz}$ system also provided information on particulate concentrations in the water column. A boatmounted $600 \mathrm{kHz}$ RDI Acoustic Doppler Current Profiler (ADCP) was used to map current velocity and direction and water column backscatter intensity along another 29 $\mathrm{km}$, with select measurements made to characterize variations in circulation with tides. An underwater video camera was deployed to ground-truth acoustic data. Seventy one sediment samples were collected to quantify sediment grain size distributions across Westcott Bay. Sediment samples were analyzed for grain size at the Western Coastal and Marine Geology Team sediment laboratory in Menlo Park, CA. These data reveal that the seafloor near the entrance to Westcott Bay is rocky with a complex morphology and covered with dense and diverse benthic vegetation. Current velocities were also measured to be highest at the entrance and along a deep channel extending $1 \mathrm{~km}$ into the bay. The substrate is increasingly comprised of finer sediments with distance into Westcott Bay where current velocities are lower. This report describes the data collected and preliminary findings of USGS Cruise B-6-07-PS conducted between May 31, 2007 and June 5, 2007.
\end{abstract}




\section{Introduction}

In response to recent, extensive loss of the eelgrass $Z$. marina throughout the San Juan Islands (Berry et al. 2003; Wyllie-Echeverria et al. 2003), scientists from Washington State Department of Natural Resources (WADNR) Aquatic Resources Division, University of Washington (UW), and the U.S. Geological Survey (USGS) have initiated studies of nearshore habitat structure and hydrodynamic processes to examine possible stressors. A principal hypothesis for the loss of Z. marina in Westcott Bay, San Juan Island, is a recent decrease in light availability for eelgrass growth due to increase in turbidity associated with either an increase in fine sedimentation or biological productivity within the bay. To examine conditions influencing possible Z. marina recovery in Westcott Bay $Z$. marina transplant studies were paired with time-series water column property measurements during the summer of 2007 as part of the WA DNR "Eelgrass Stressor-Response Project”. To characterize sources and processes influencing sediment transport and turbidity that affect light conditions for Z. marina, bathymetric, substrate, and circulation mapping were conducted. This report describes the bathymetry, substrate, and circulation data collected and preliminary findings that relate to the nearshore and Z. marina habitat in Westcott Bay.

\section{Study Area}

Westcott Bay is located along the northwest coast of San Juan Island (Figure 1).

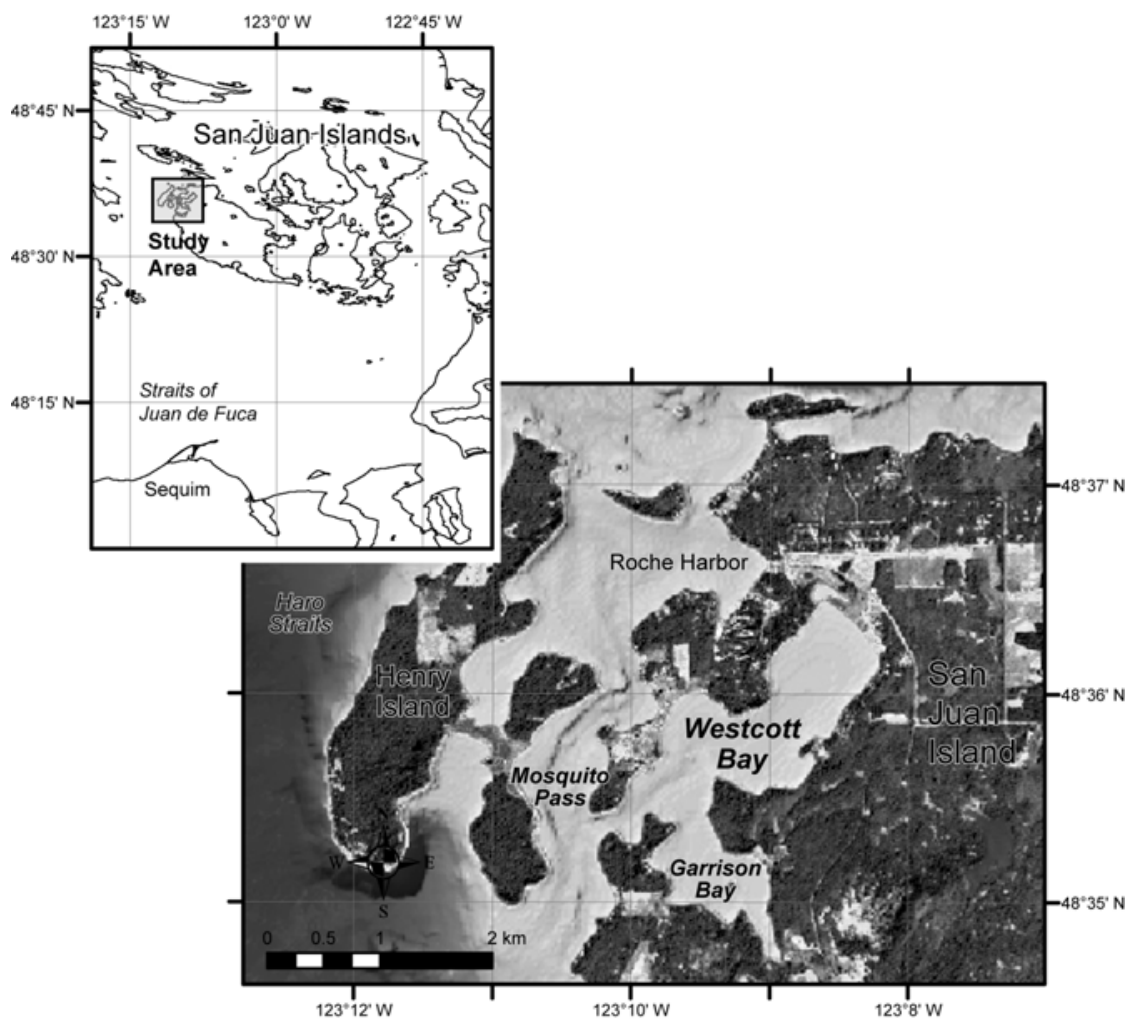

Figure 1. Location map showing Westcott Bay study area. 
Westcott Bay is $3 \mathrm{~km}$ in length and averages $800 \mathrm{~m}$ in width and is connected to Garrison Bay inside of a narrow (150 m) mouth opening into Mosquito Pass. Westcott Bay is relatively shallow reaching a maximum depth of approximately $-8.5 \mathrm{~m}$, although $35 \%$ of the bay is less than $-2 \mathrm{~m}$ and $48 \%$ is less than $-3 \mathrm{~m}$. It is bounded by a relatively low relief watershed composed of Paleozoic and Mesozoic sedimentary rocks that have been folded into a broad syncline, some of which have been metamorphosed by igneous rocks of Mesozoic age. Two small intermittent streams discharge into the head of the bay. Westcott Bay is oriented WSW-ENE and because of its narrow mouth, receives little swell in the form of wind waves originating from summertime northwest and periodic wintertime southwest fetch. This region of the San Juan Islands is characterized by a 3.5$4.0 \mathrm{~m}$ tide regime which generates strong observable tidal currents in Mosquito Pass. Sediment sources for Westcott Bay are likely to include fluvial-derived sediment input from the two small streams, erosion of bedrock outcrops near headlands and along the seafloor, autochthonous organic matter and calcareous shell production, and possibly import of fine materials from outside the bay through advection.

\section{Data Acquisition}

\section{Bathymetric mapping}

Sixty-nine (69) kilometers of acoustic bathymetry/substrate data were collected with a dual-frequency (200 and $430 \mathrm{kHz}$ ) Biosonics DT-X sonar system along 142 transects in Westcott and Garrison Bays between 5/31/07 and 6/2/07 (Fig. 2, Appendix 1).

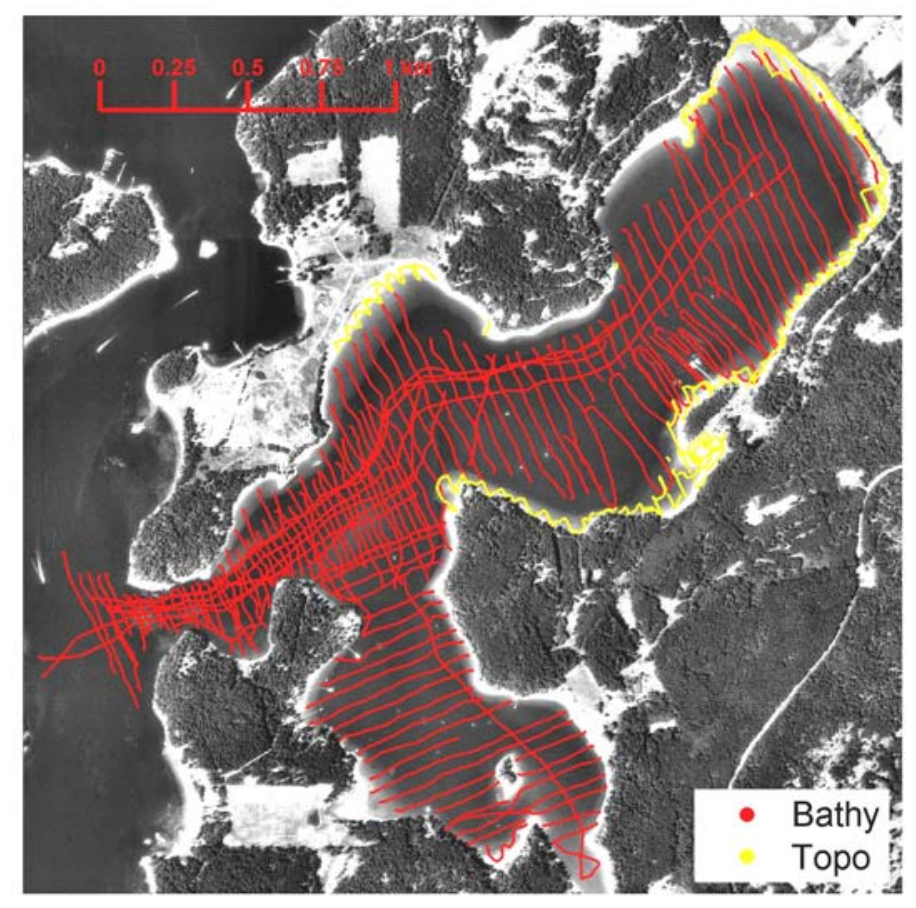

Fig. 2. Map of survey track lines where bathymetry and acoustic substrate data (red) and topographic RTK-DGPS data (yellow) were collected 
The Biosonics sonar generates a 6-degree cone of sound, which translates into a footprint on the seafloor ranging 0.2 to $0.8 \mathrm{~m}$ for the water depths surveyed (2 - $8 \mathrm{~m}$ ). Ship speed generally ranged 4.0-4.5 kts and data were merged with GPS positions at $1 \mathrm{~Hz}$. Resulting data therefore represent $0.2-0.8 \mathrm{~m}$ pixels on the seafloor spaced approximately 1-2 $\mathrm{m}$ apart along track lines. Track lines were spaced $25 \mathrm{~m}$ apart. Twenty (20) km of topographic elevation data were also collected across the upper intertidal region by walking the shoreface with a portable Trimble 4700 RTK-DGPS receiver. This receiver utilized a Trimble Zepher Antenna and Pacific Crest radio receiver to obtain real time position corrections from a base station operating a Trimble 4400 receiver and L1/L2 antenna with a Pacific Crest 35 Watt radio transmitter. Elevation data over emergent beaches and tide flats collected by walking are 2-3 times denser as a result of survey speeds ranging $0.5-1.0 \mathrm{kts}$. The combined bathymetric and topographic data were merged to create a digital elevation model representing the surface topography of Westcott Bay. This surface is referenced to the WGS 84 datum in the UTM Zone 10 North projection with a horizontal accuracy of $2.3 \mathrm{~cm}$. Elevations are referenced to NAVD88 with an estimated vertical accuracy ranging 2.6-9.8 cm. This includes error from the RTK-DGPS and Biosonics sonar, and errors introduced in data processing. The root mean square (RMS) error of the processed surface elevation values were derived from survey line crossings. Line crossings did not always capture the same point on the seafloor (because of GPS accuracy, navigation, currents, and timing of data recording). Therefore, variability in elevation values at crossings is likely in part derived from variability in the bathymetry of the seafloor where line crossings spanned 0.5 to $2 \mathrm{~m}$ apart in the horizontal.

Because there can be significant natural variability in depth/elevation across 0.5 to 2.0 $\mathrm{m}$ of the seafloor, the vertical error of the survey was determined from analysis of three classes of elevation values at line crossings:

1) values within $2 \mathrm{~m}$ of each other from all areas of Westcott Bay including vegetated, rocky and smooth areas (RMS $=9.8 \mathrm{~cm}, \mathrm{n}=66$ )

2) values within $2 \mathrm{~m}$ of each other from the smooth area between Bell Point and the head of Westcott Bay (RMS=3.6 cm, n=22)

3) values within $0.5 \mathrm{~m}$ of each other within the smooth area between Bell Point and the head of Westcott Bay (RMS=2.6 cm, n=6)

The overall error for the entire survey is therefore $9.8 \mathrm{~cm}$, although particular areas, especially characterized by low relief likely have much smaller errors.

\section{Sediment Samples for Grain Size Analyses}

Sediment samples were collected using a van veen grab sampler at 71 stations on a 200-250 m grid (Fig. 3) to characterize grain size distribution throughout Westcott Bay and sources of fine material for suspension and transport. 


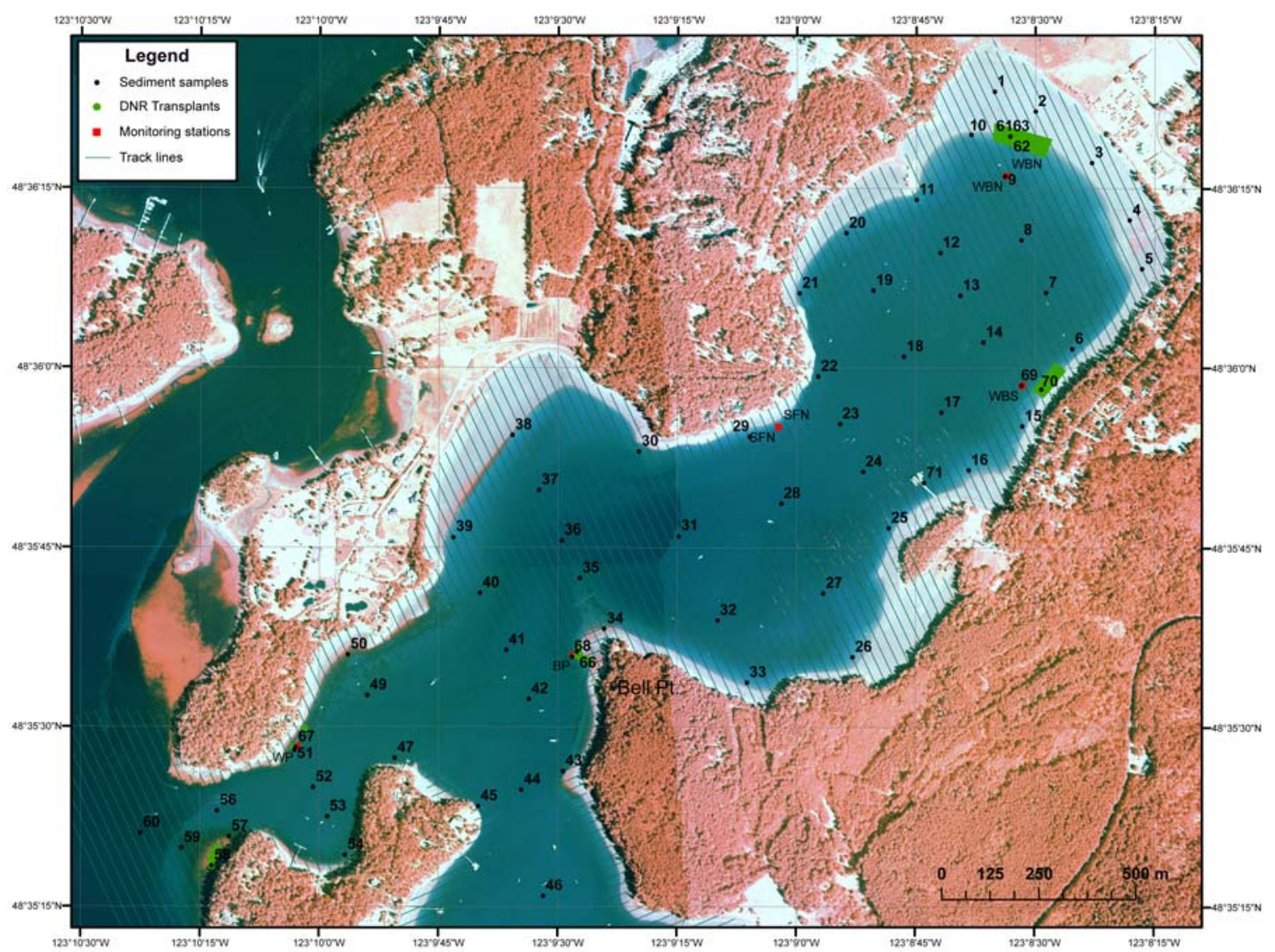

Fig. 3. Map showing sediment grab sample locations.

The shallow stratigraphy was well-preserved in the sediment grabs so that a $1-3 \mathrm{~cm}$ thick aerated surface layer could be observed at most stations dominated by fines (Figure 4).

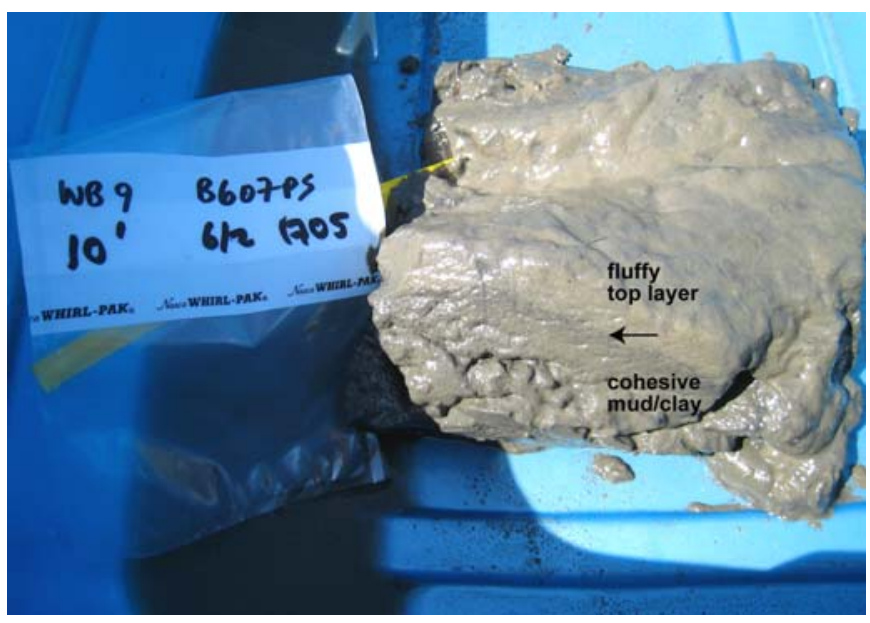

Fig. 4. Photo of sediment grab sample WB9 showing fluffy, light colored, aerated top layer overlying a sharp contact (arrow) with a denser, cohesive mud/clay below. 
In the field, a sub-sample of the uppermost 1-3 cm of each grab was collected and placed into storage bags, labeled, logged, and frozen. Several 10-cm push cores were also collected. Triplicate samples were collected at sites WBN and BP for error analyses. Appendix 2 summarizes sample times and environmental conditions at collection sites.

In the laboratory, sediment samples were split for grain size and carbon analyses and later archived at the Western Coastal and Marine Geology Team sediment laboratory in Menlo Park, CA. Samples were disaggregated and sieved through 2000 and 62 micron screens to separate gravel, sands and mud after the organic component was removed by treatment with hydrogen peroxide. Sediment grain size of sands was determined using the settling methods and principles of Stokes Law (Guy 1969) on the USGS 3-m long settling tubes. The fine fraction (silts and clays) were analyzed on a Coulter 230 Laser Particle Analyzer. Three samples had less than 3\% intermediate fraction and were analyzed on the Coulter. Single sample runs were made on the tubes, while results from the laser particle analyzer are averages of triplicates with standard deviations around the mean ranging 18 to 24 microns due to instrument errors. Results from the tubes and laser particle analyzer were merged using standard USGS methods found in the USGS particle analysis program pcSedSize http://water.usgs.gov/software/sedsize.html). Analyses of triplicate samples collected at stations WBN and BP show that inter-station variability around the mean grain size ranged $\pm 0.054 \mathrm{~mm}$. The complete grain size results are provided in Appendix 3. These results were then gridded across the bathymetric surface with a nearneighbor gridding algorithm averaging between the three nearest points.

Video of the seafloor was collected along several principal transects in the western and central portions of Westcott Bay to ground-truth the sonar data and provide direct observations of the complex substrate, substrate transitions, and benthic vegetation. These results will be furnished in subsequent revisions to this report.

\section{Nearshore Currents}

Current velocity, direction and backscatter amplitude were collected along 65 transects in Westcott Bay (Fig. 5) with a $600 \mathrm{kHz}$ RDI ADCP (Acoustic Doppler Current Profiler) and recorded with WinRiver software following Oberg and others, (2005). Select transects at the mouth of Westcott Bay, Bell Point and immediately east of the Westcott Sea Farm were repeated 2-3 times under flooding and ebbing tides. ADCP were recorded with GPS position at $1 \mathrm{hz}$ with a ship speed of 2.0-2.5 kts, so raw ADCP data cover a lateral distance of 1.00 to $1.25 \mathrm{~m}$. The raw ADCP data were vertically binned at $0.25 \mathrm{~m}$ and include a blanking distance of $0.25 \mathrm{~m}$ (no data in uppermost $0.25 \mathrm{~m}$ below the transducer). The RDI ADCP is accurate to within $0.25 \%$ of boat + water velocity, resulting in an error for our velocity data of 0.25 to $0.45 \mathrm{~cm} / \mathrm{s}$ based on our survey speed of $2 \mathrm{kts}$ and measured velocities ranging 0 to $1.5 \mathrm{~m} / \mathrm{s}$. 


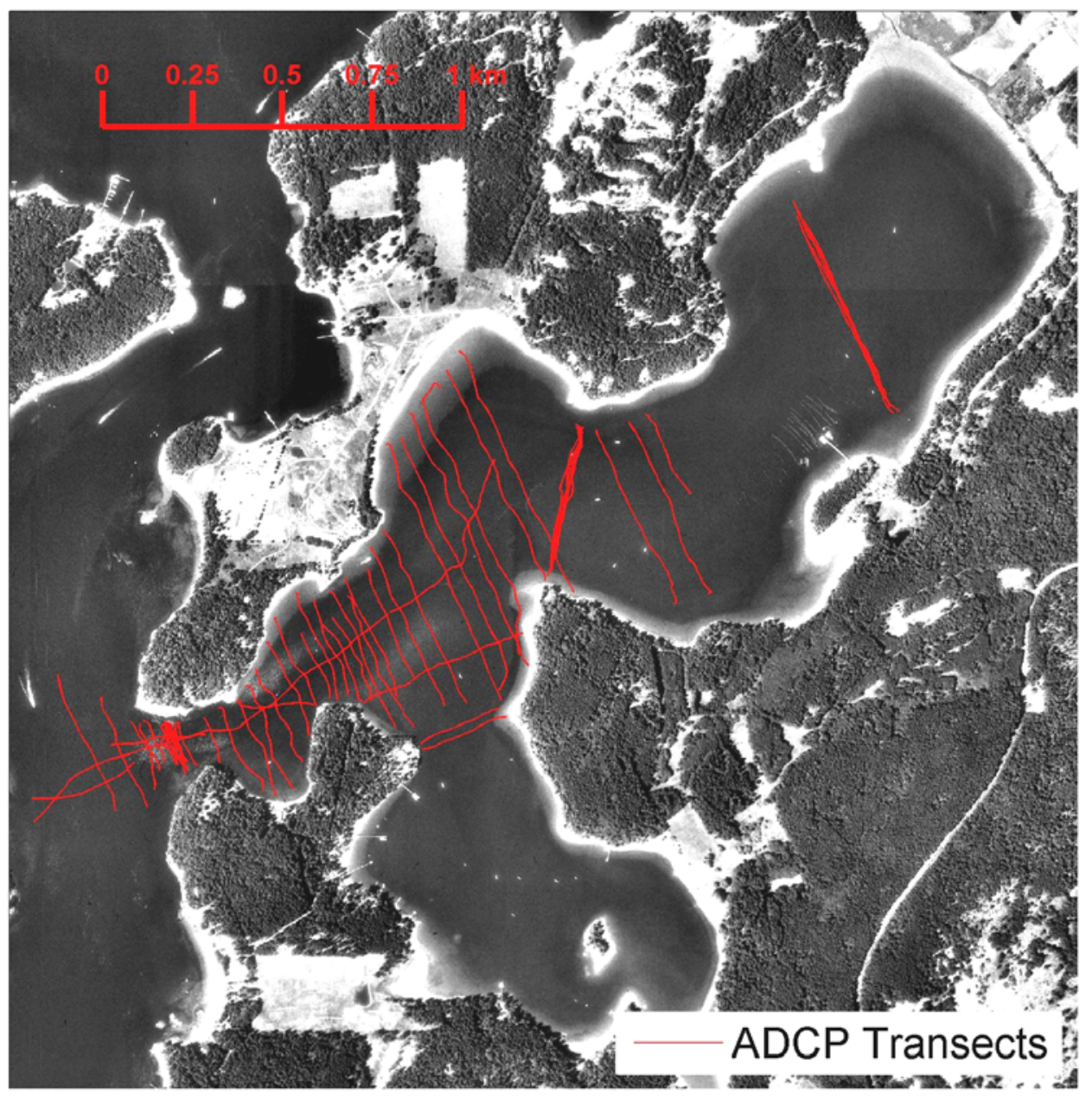

Fig. 5. Map of ADCP survey lines. Three principal lines (bold lines) at the mouth of Westcott Bay, Bell Point and just east of the sea farm were repeated multiple times to examine variability under ebb and flood tides.

\section{Results}

\section{Bathymetry and geomorphology}

The resulting bathymetric surface map derived from the combined DGPS and biosonics sonar data shows that the seafloor of Westcott Bay is complex with high relief between the entrance at Mosquito Pass and Bell Point, while the head of the bay is shallow, smooth and lacking relief (Fig. 6). A distinct narrow channel incises to $-8.5 \mathrm{~m}$ along the central axis of the outer bay and is deeper along the north edge of the entrance to the bay. A sill 7-8 m deep separates Mosquito Pass from Westcott Bay. The channel/trough extends east to the area north of Bell Point, where it gradually shallows 
toward the head of the bay. The margins of the trough are relatively steep, exceeding 35$40 \%$ slope immediately southeast of White Point (Fig. 7). These complex sill and trough features are likely a result of complex and strong currents, the presence of rocky substrate at the seafloor, and the regional glacial history. The bathymetry between Bell Point and the head of the bay is relatively smooth and featureless likely reflecting extensive sedimentation of fine material.

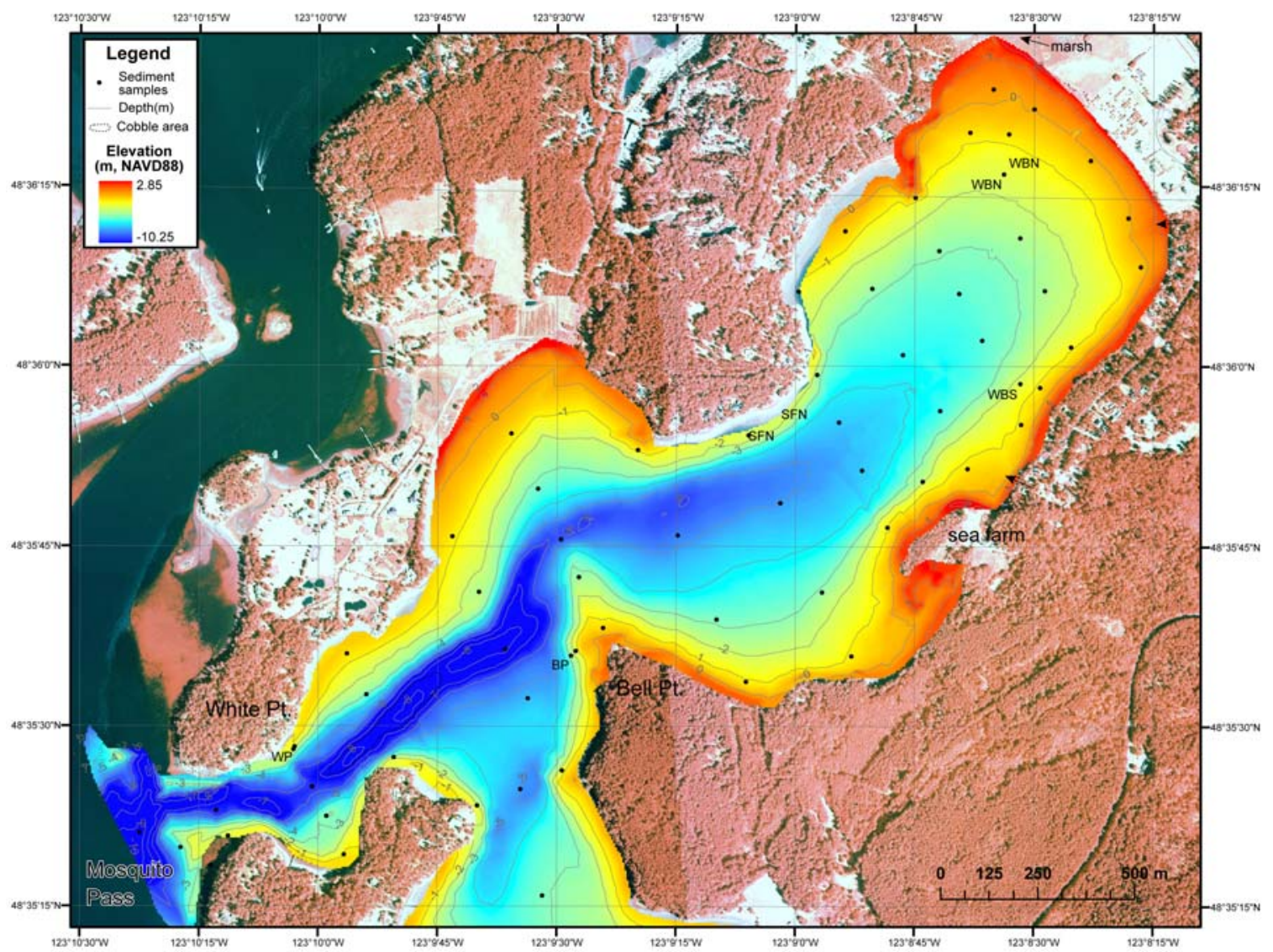

Fig. 6. Surface map of Westcott Bay based on bathymetry and topographic data collected showing narrow linear deep trough along center axis of outer Westcott Bay and shallow smooth surface of the head of the bay. 


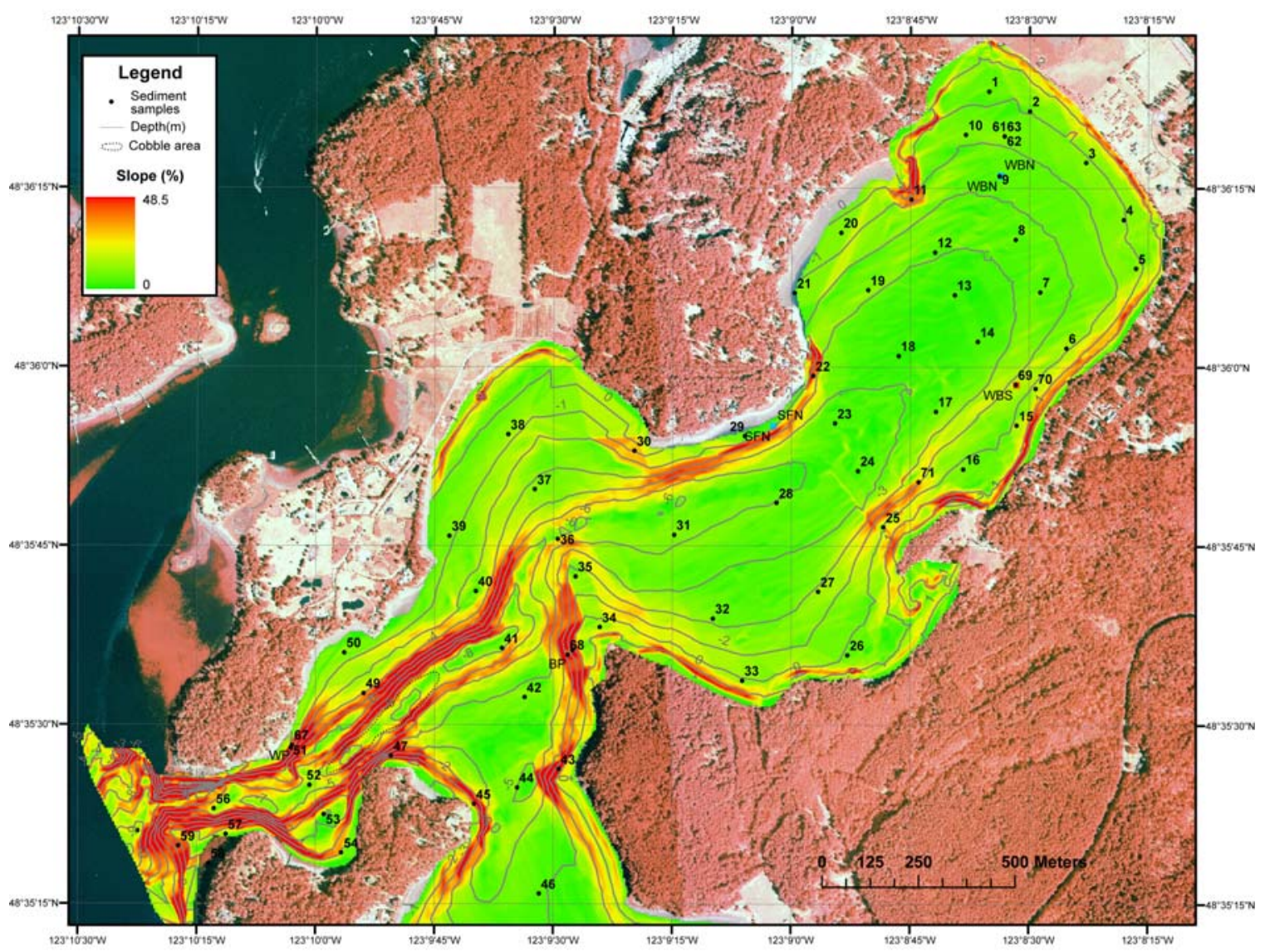

Fig. 7. Map showing seafloor slope of Westcott Bay with steep slopes characterizing the complex sill and trough region of the western half of the bay and relatively low slopes common of the broad gentle seafloor at the head of the bay. 


\section{Sediment grain size distribution}

Figure 8 shows the mean grain size distribution in mm of unconsolidated sediments across Westcott Bay. Although the substrate was generally rocky in Mosquito pass and at the mouth of Westcott Bay, sand occurred within what appeared to be thin veneers of surface sediments. This region supported diverse communities of large kelp, seaweeds and algae. Along the central channel extending from Mosquito Pass to Bell Point, video observations along with grain size analyses indicated that the bottom was characterized by coarse sediments including gravel and cobbles. This region is delineated on all subsequent grain size distribution maps with a dotted polygon. Sand also dominates unconsolidated materials on the seafloor at the entrance to Garrison Bay, and near the intermittent stream mouths at the head of the bay and at the inlet to the marsh at the northeast corner of the bay. Otherwise silt predominates as the mean grain size throughout the central region and head of the bay.

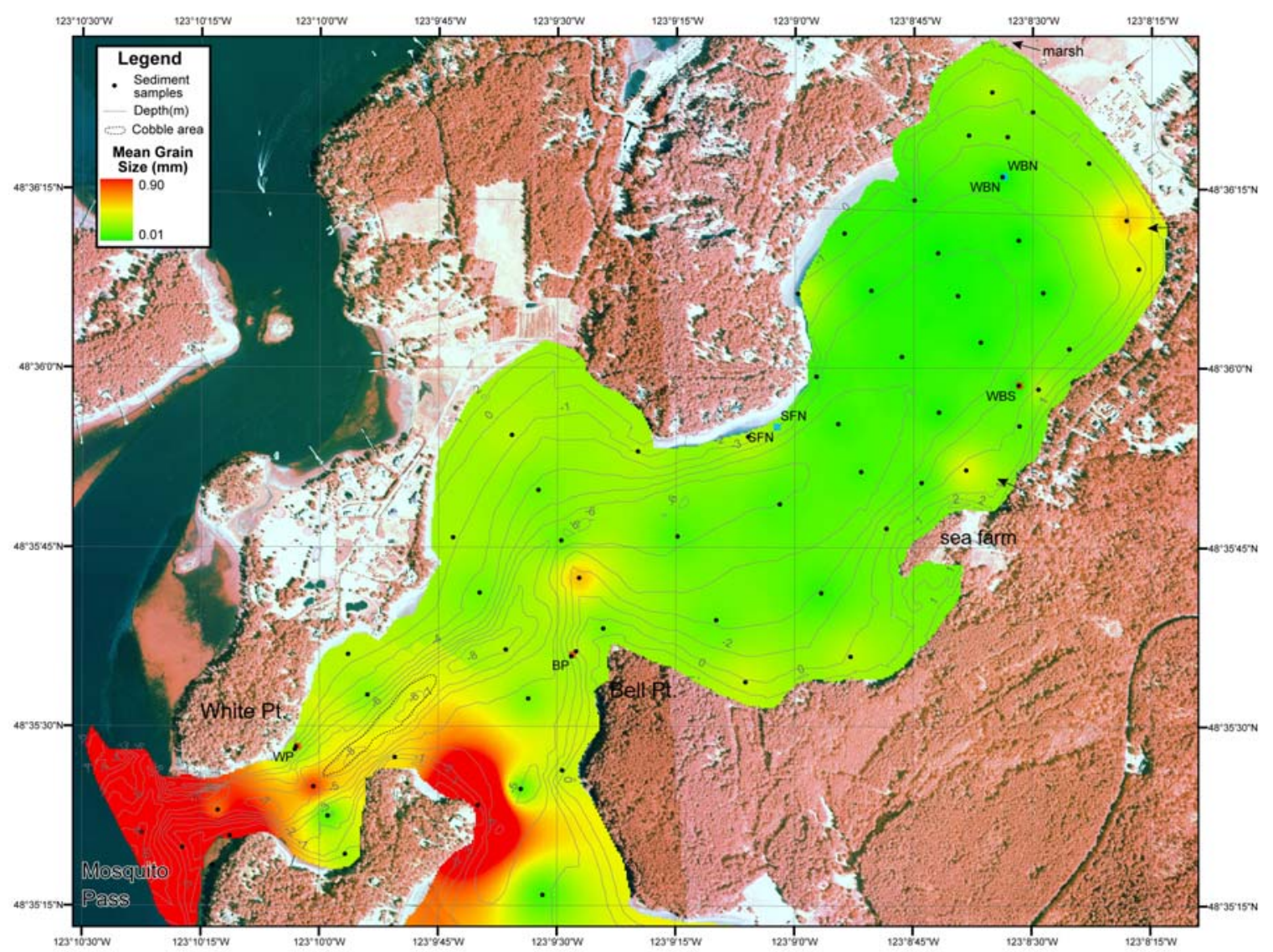

Fig. 8. Map of mean grain size in mm across the study area. Cobble- and pebble-rich channel outlined in black dotted polygon; streams shown with black arrows. 
Figure 9 shows the mean grain size in mm classified by predominant grain size classes. This better shows the isolation of medium sands and coarser material near the entrance to Westcott and Garrison Bays, and fine silts in the central head of the bay. Exceptions to this include very fine to fine sand along the shoreline at the head of the bay likely associated with the two creeks and lagoon that meet the shore there.

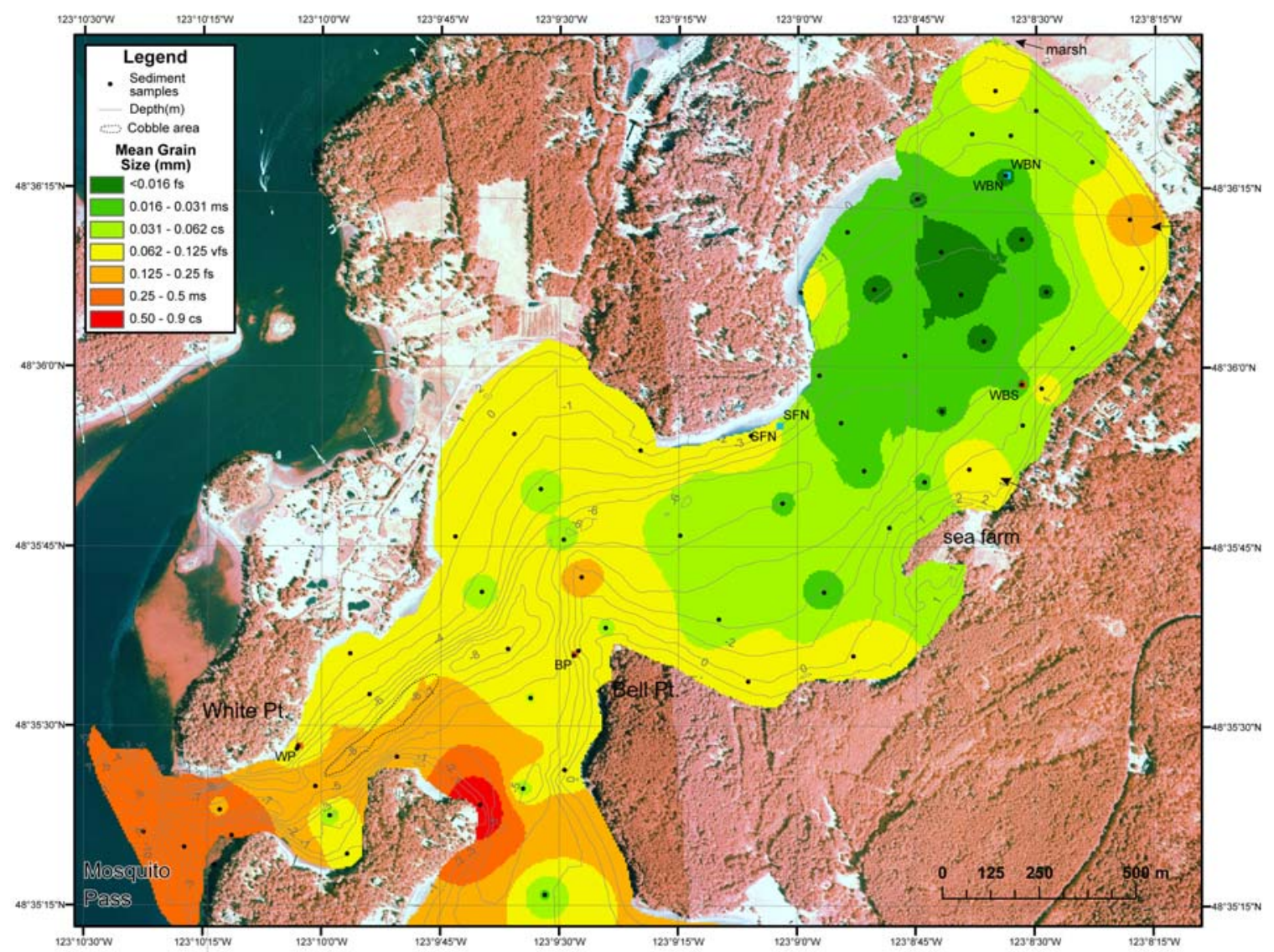

Fig. 9. Map of mean grain size classified by classes (in $\mathrm{mm}$ ) across the study area. In order of increasing size (top to bottom) beginning with $<0.016 \mathrm{~mm}$, fs=fine silt, ms-medium silt, $\mathrm{cs}=$ coarse silt, vfs=very fine sand, fs=fine sand, $\mathrm{ms}=$ medium sand, 0.5-0.9 cs=coarse sand. Cobble- and pebble-rich channel outlined in black dotted polygon; streams shown with black arrows. 
Figure 10 shows the mean grain size distribution in phi units, which allows for slightly greater dynamic range in display of the size gradients. Similar to figure 8 , sands are restricted to the mouth and entrance to Garrison Bay, as well as, the small intermittent stream mouths at the head of the bay. Silt dominates the center and head of the bay.

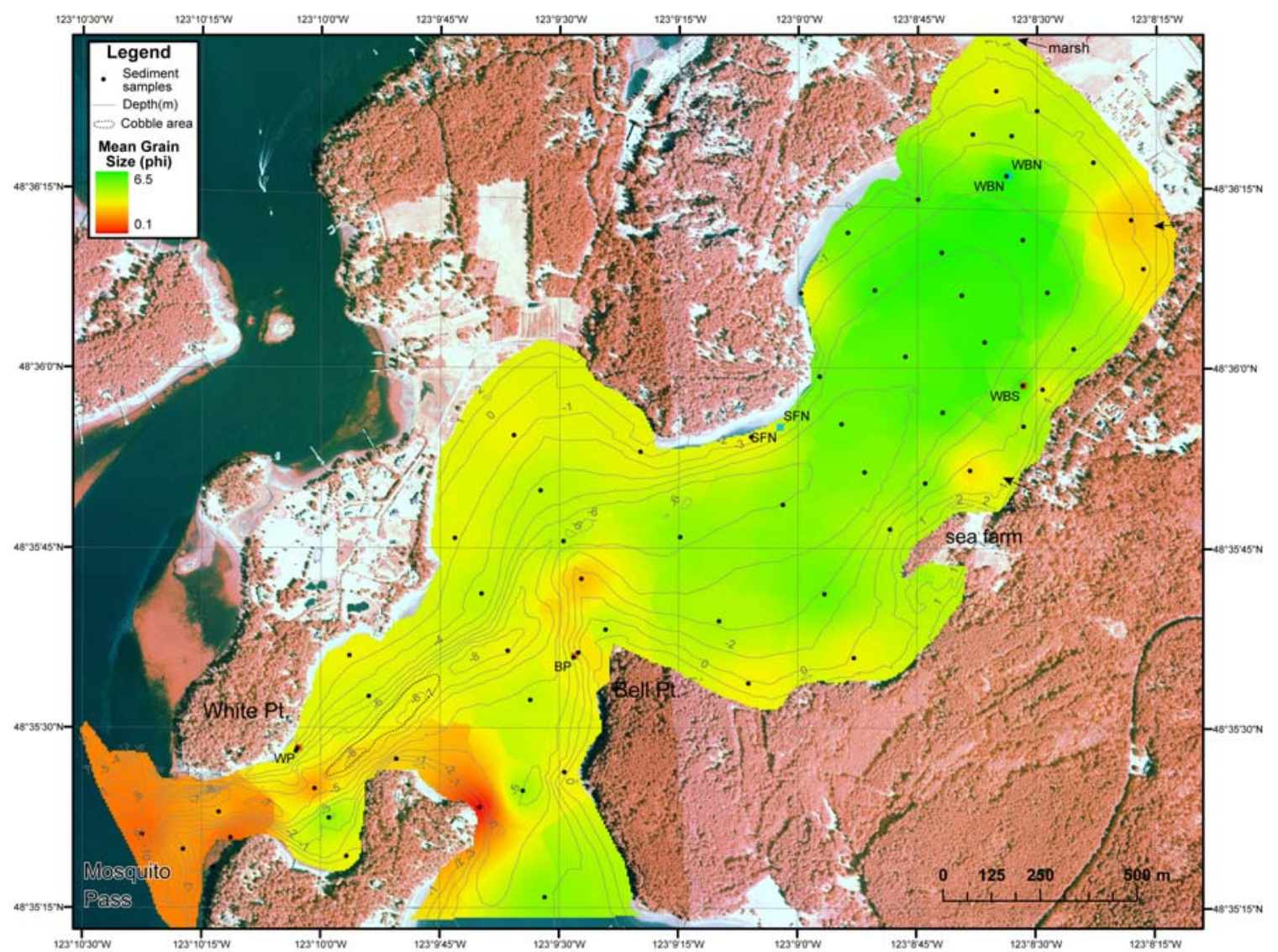

Fig. 10. Map of mean grain size in phi units across the study area. Cobble- and pebble-rich channel outlined in black dotted polygon; streams shown with black arrows. 
Figure 11 displays the mean grain size in phi units classified by dominant grain size classes. This also shows that medium and coarse sands occur near the mouth and entrance to Garrison Bay, and fine silts dominate in the central head of the bay, except along the shore at the head of the bay where fine sand is associated with the mouth of the intermittent streams.

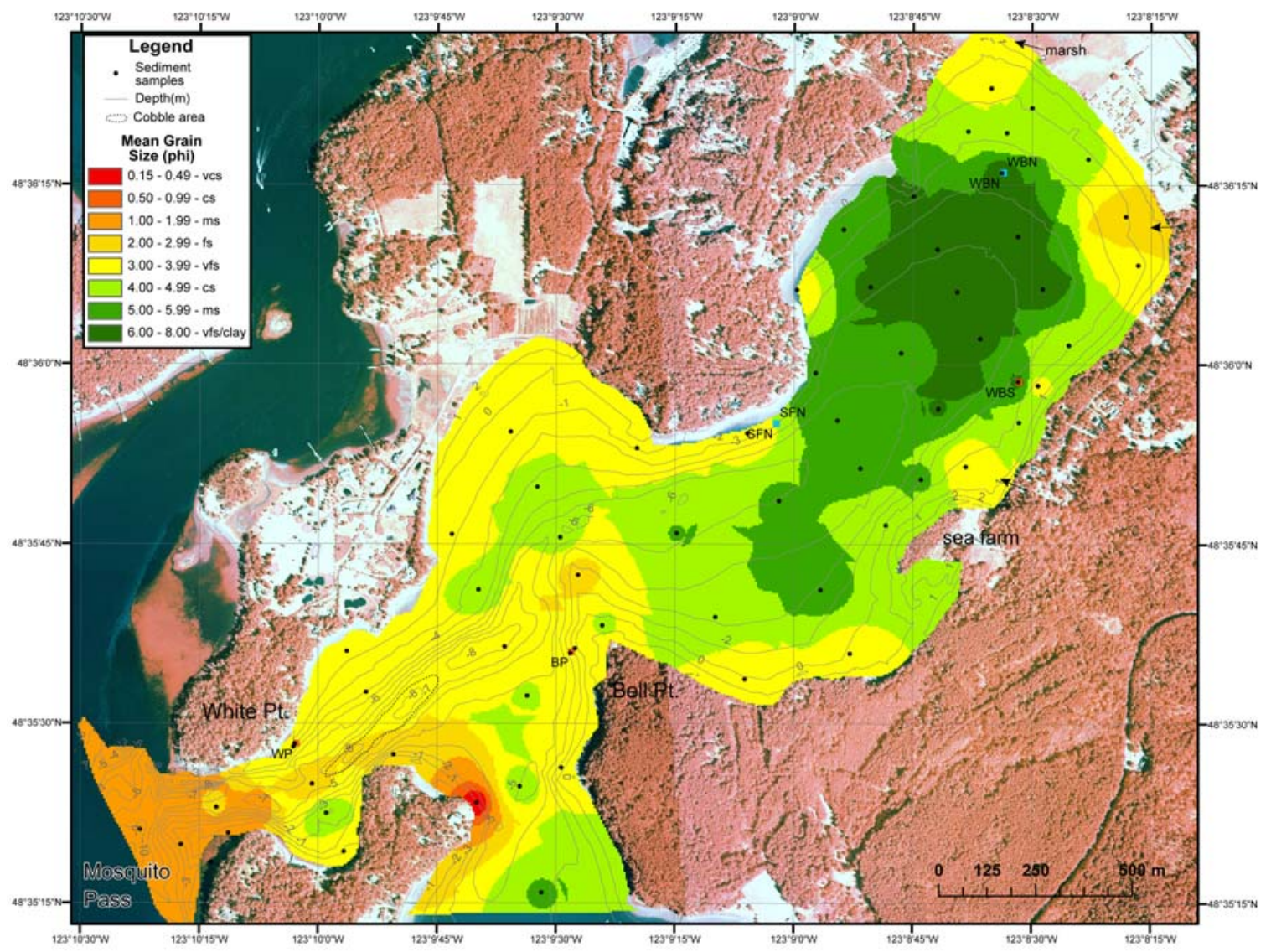

Fig. 11. Map of mean grain size classified by classes (in phi) across the study area. In order of decreasing size (top to bottom) beginning with $0.15-0.49$ vcs=very coarse sand, $c s=$ coarse sand, $\mathrm{ms}=$ medium sand, fs=fine sand, vfs=very fine sand, $\mathrm{cs}=$ coarse silt, ms=medium silt, vfs/clay=very fine silt/clay. Cobble- and pebble-rich channel outlined in black dotted polygon; streams shown with black arrows. 
Figure 12 shows the degree of sorting of surface sediments across Westcott Bay. This is the calculated standard deviation around the mean grain size. Poorly sorted areas are reflected in the warm (red) colors, while well sorted areas are depicted in cool (blue) colors. Poorly sorted sediments were common immediately inside Westcott Bay across an inverted, u-shape area around the entrance to Garrison Bay. Sediments were generally poorly sorted along the eastern central bay and at the far head of the bay. Sediments were well-sorted along the central axis in the head of the bay and at the easternmost stream mouth and lagoon inlet. Sediments were generally well sorted inside the entrance to Garrison Bay. These variations in sorting are likely associated with strong circulation processes that oscillate in and out of the bay daily and sediment sources (e.g. the intermittent streams). Sediments were generally poorly sorted near the sea farm.

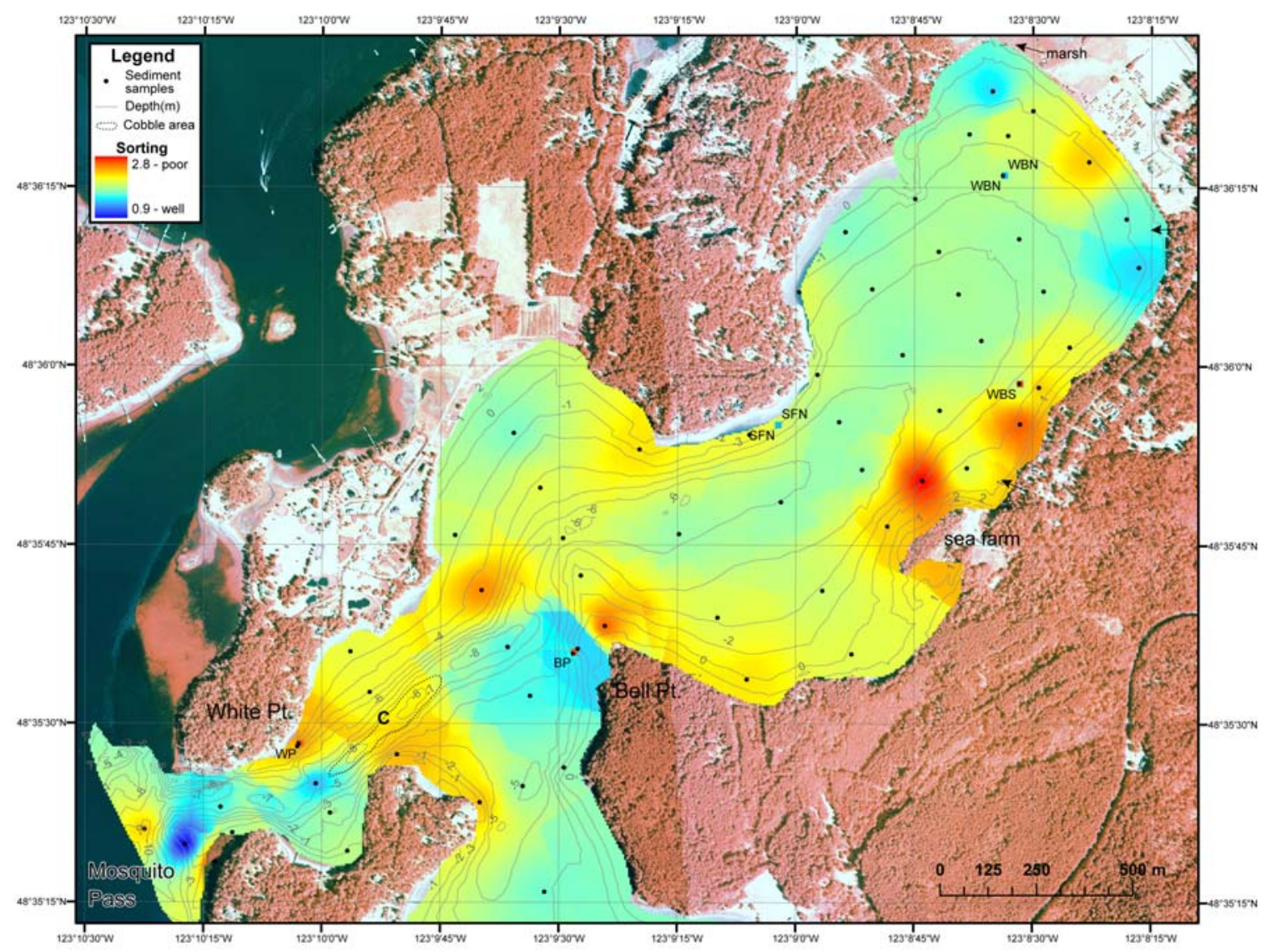

Fig. 12. Map of sediment sorting across the study area. Poorly sorted sediment are represented with warm (red) colors; well-sorted sediments with cool (blue) colors. Cobble- and pebble-rich channel outlined in black dotted polygon; streams shown with black arrows. 
Figure 13 shows the fraction of sand in surface sediments across Westcott Bay in percent of total size classes. At the mouth of the bay and small intermittent stream, sand makes up $>80 \%$ of seafloor sediment. In the central bay west of Bell Point, sand comprises generally $>50 \%$ of all material, while to the east toward the head of the bay sand reaches a low of $5 \%$.

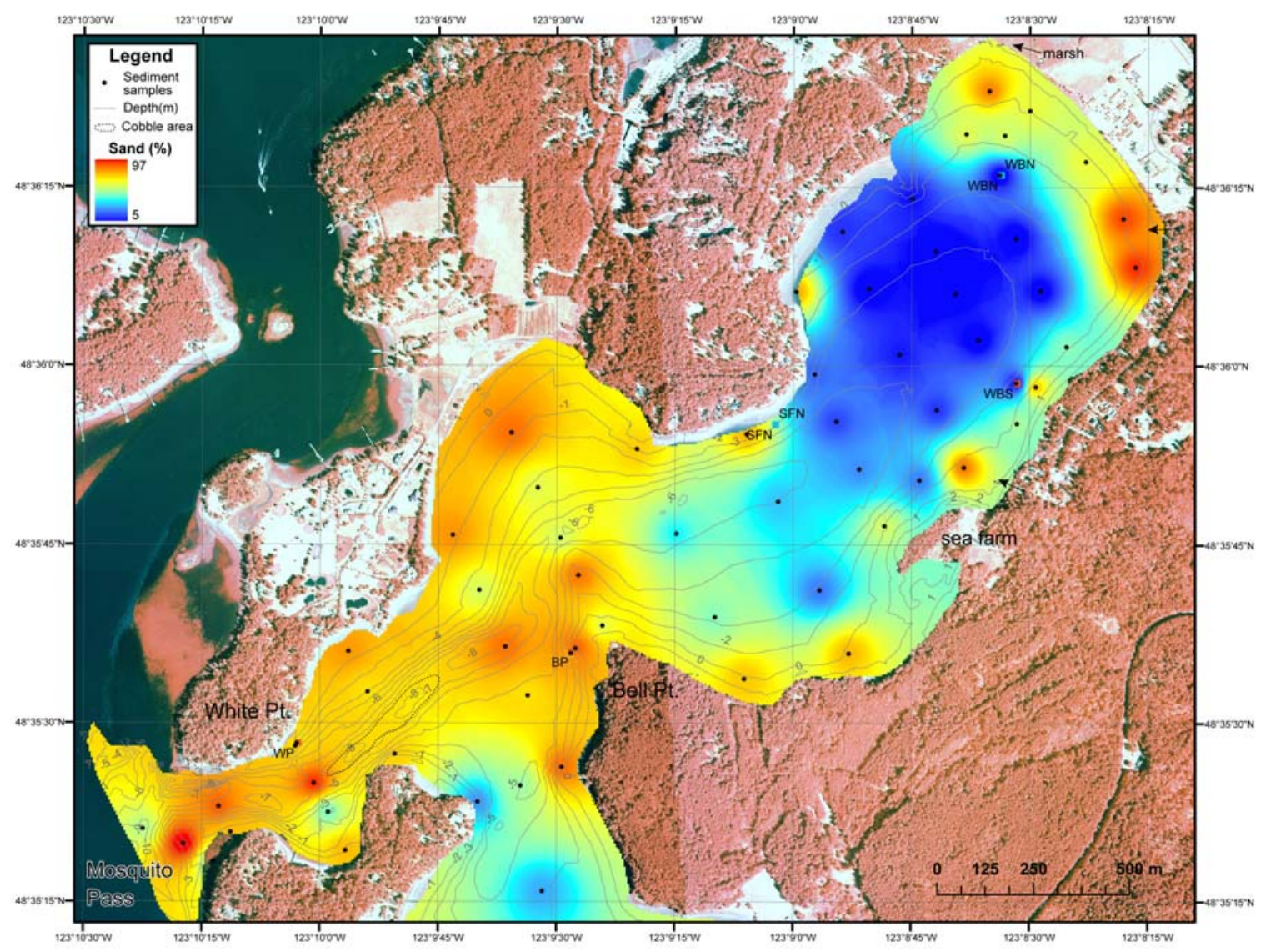

Fig. 13. Map of percent sand occurrence across the study area. Cobble- and pebble-rich channel outlined in black dotted polygon; streams shown with black arrows. 
Figure 14 shows the fraction of silt in surface sediments across Westcott Bay in percent of total size classes. Silt is clearly restricted to the areas within Garrison Bay and within the head of Westcott Bay where it reaches a maximum of 76\%. East of Bell Point, silt generally comprises at least $50 \%$ of the sediment.

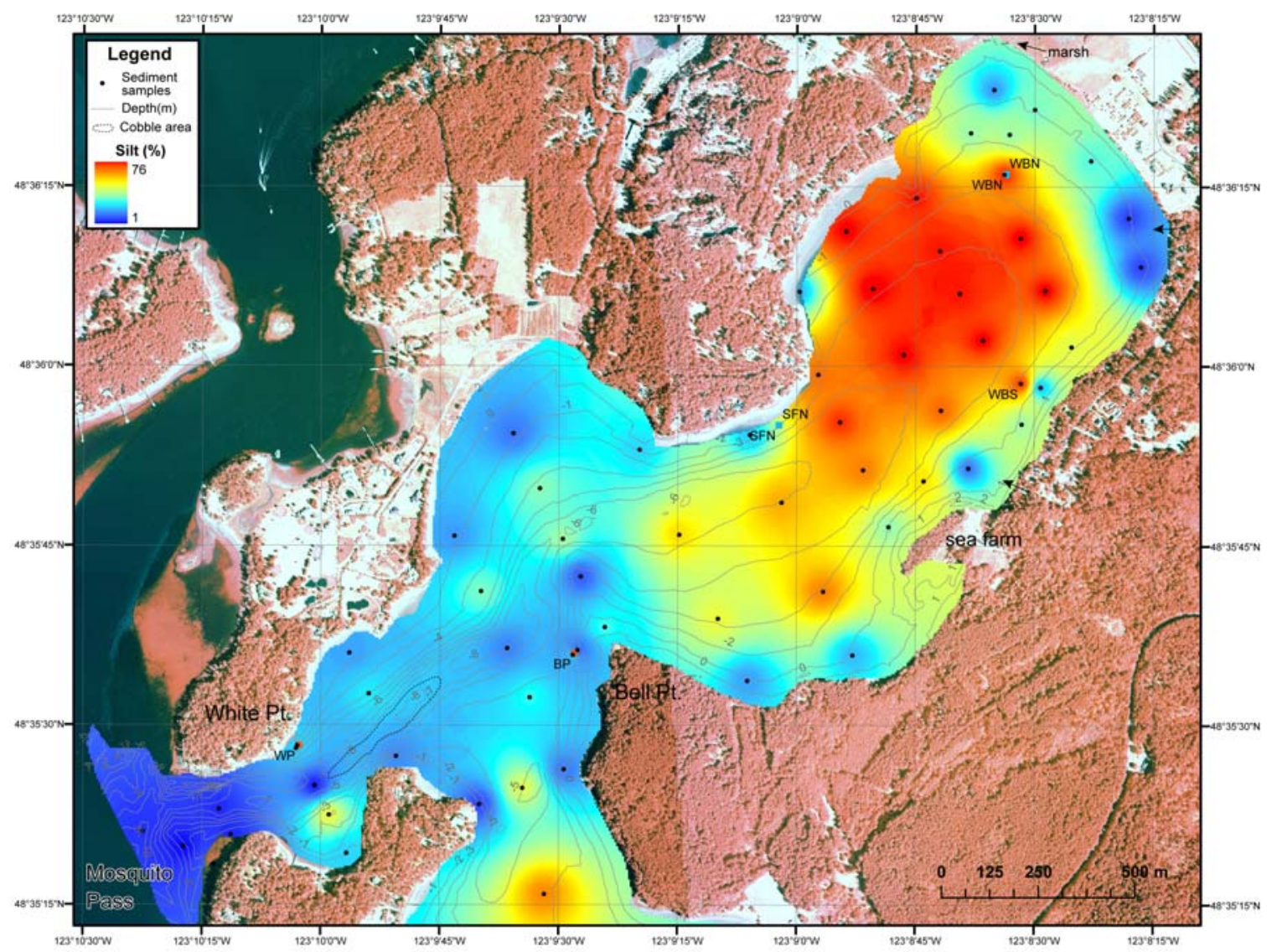

Fig. 14. Map of percent silt occurrence across the study area. Cobble- and pebble-rich channel outlined in black dotted polygon; streams shown with black arrows. 
Figure 15 shows the fraction of clay in surface sediments across Westcott Bay in percent of total size classes. Clay is largely absent west of Bell Point, except for two isolated stations just northwest of Bell Point where it reaches $\sim 10 \%$. Within the head of the bay, clay comprises up to $21 \%$ of the sediment.

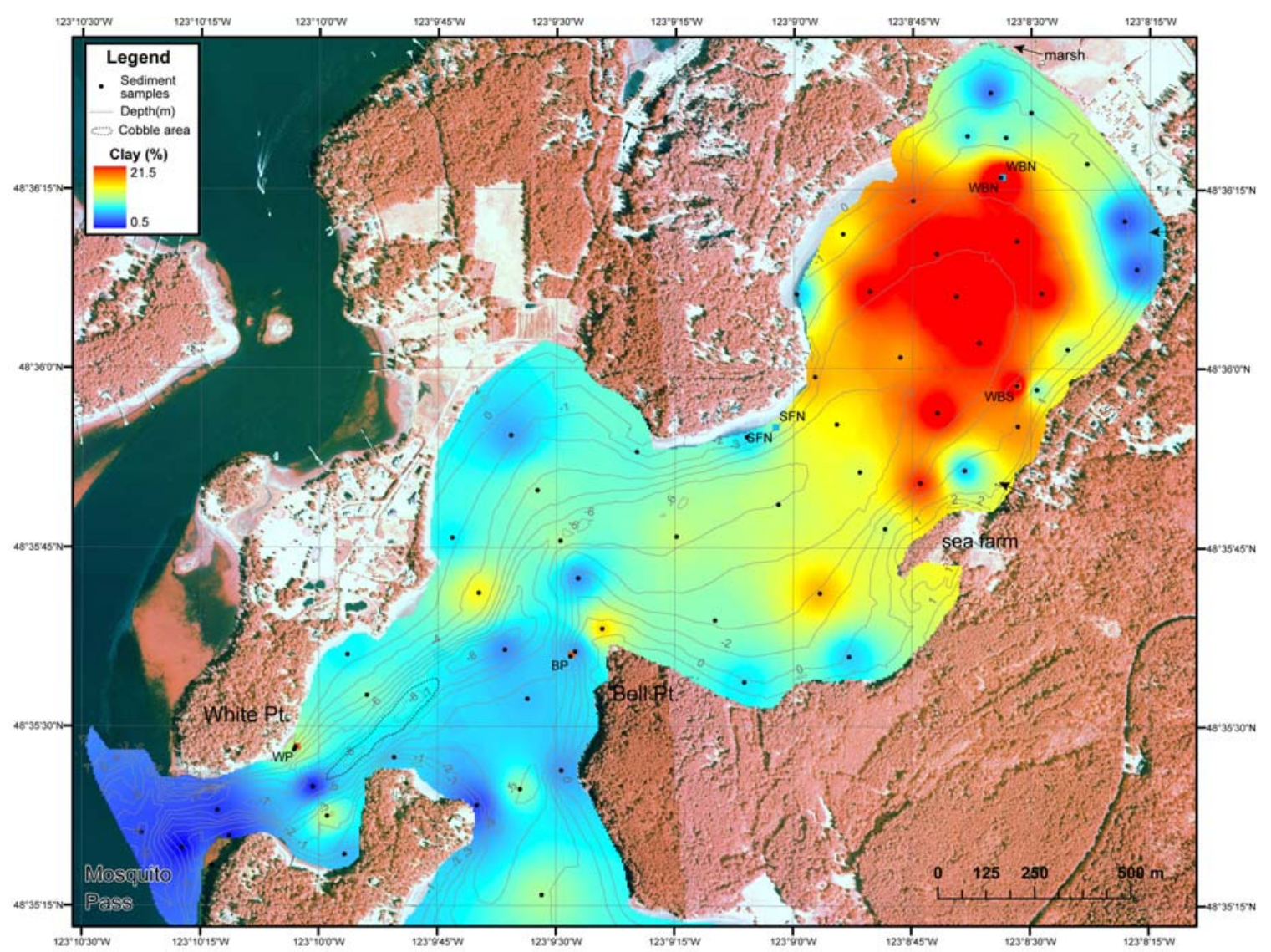

Fig. 15. Map of percent clay occurrence across the study area. Cobble- and pebble-rich channel outlined in black dotted polygon; streams shown with black arrows.

In summary, sand size sediment dominates at the mouth of Westcott and Garrison Bays and along the shoreline at the head of the bay near the small intermittent stream and lagoon inlet. Along the deep trough in the center of the bay, surficial sediments are also characterized by sand and coarse silt with outcrops of rock and cobbles. Inside Garrison Bay and the head of Westcott Bay and especially east of Bell Point, sediments are dominated by silt with a significant (15-20\%) proportion of clay. 


\section{Nearshore currents and circulation}

Figures 16 and 17 illustrate the boat-mounted ADCP-derived currents at the entrance to Westcott Bay under a flooding tide of May 31, 2007. The highest current velocities occur along the north edge of the entrance along the deep trough found there. Current velocities at the surface reached 0.75 to $1.00 \mathrm{~m} / \mathrm{s}$.

\section{1-May-2007 21:52:11}

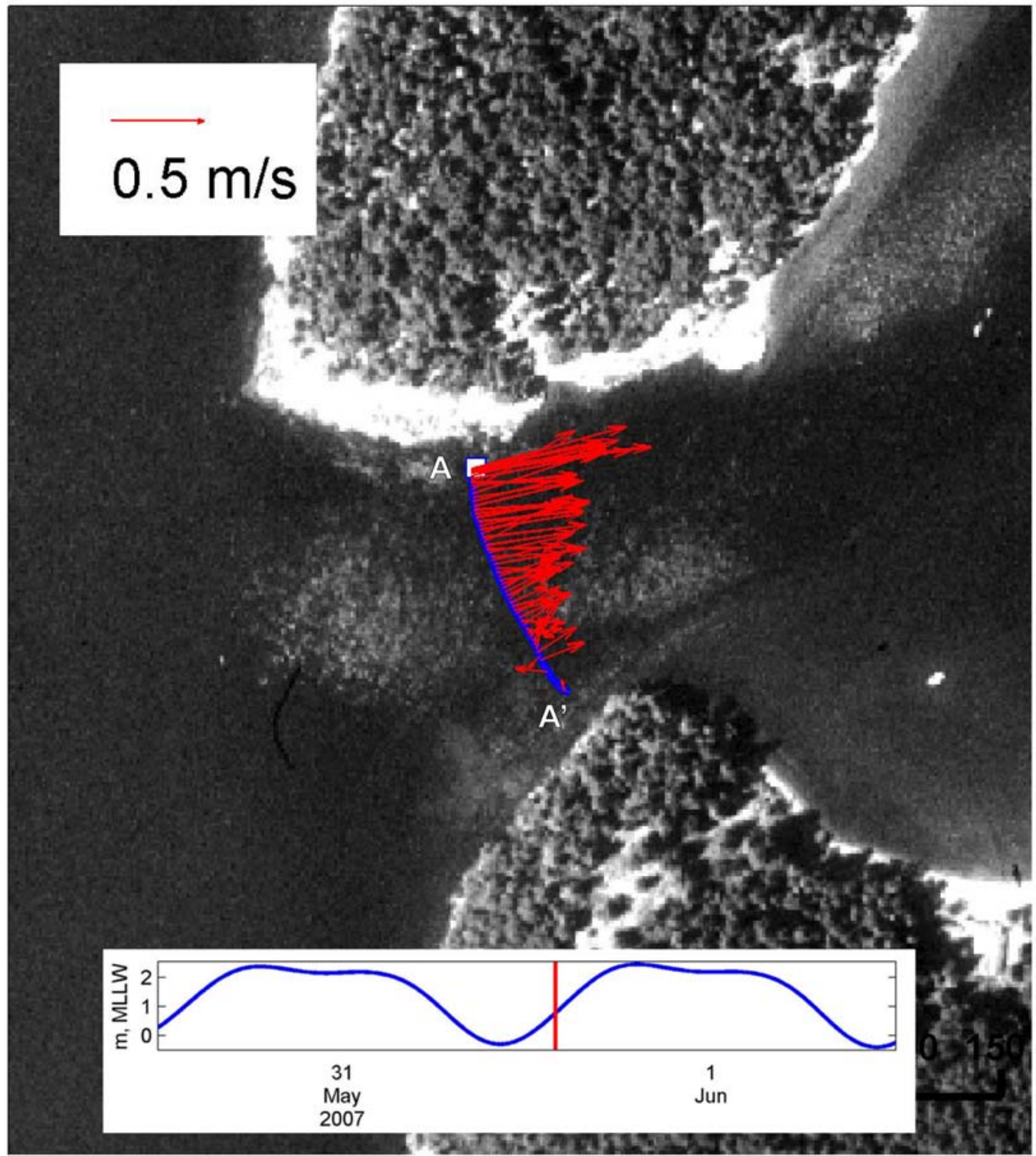

Fig. 16. Map of depth-averaged current velocity averaged across 5 ensembles (lateral distance) during flooding tide of May 31, 2007 (inset; water level from Friday Harbor tide predictions, http://tidesandcurrents.noaa.gov/data_menu.shtml?stn=9449880\%20Friday\%20Harbor,\%20WA \&type=Tide+Predictions). Current velocities were stronger along northwest edge of the entrance to Westcott Bay, likely associated with deeper trough there. 

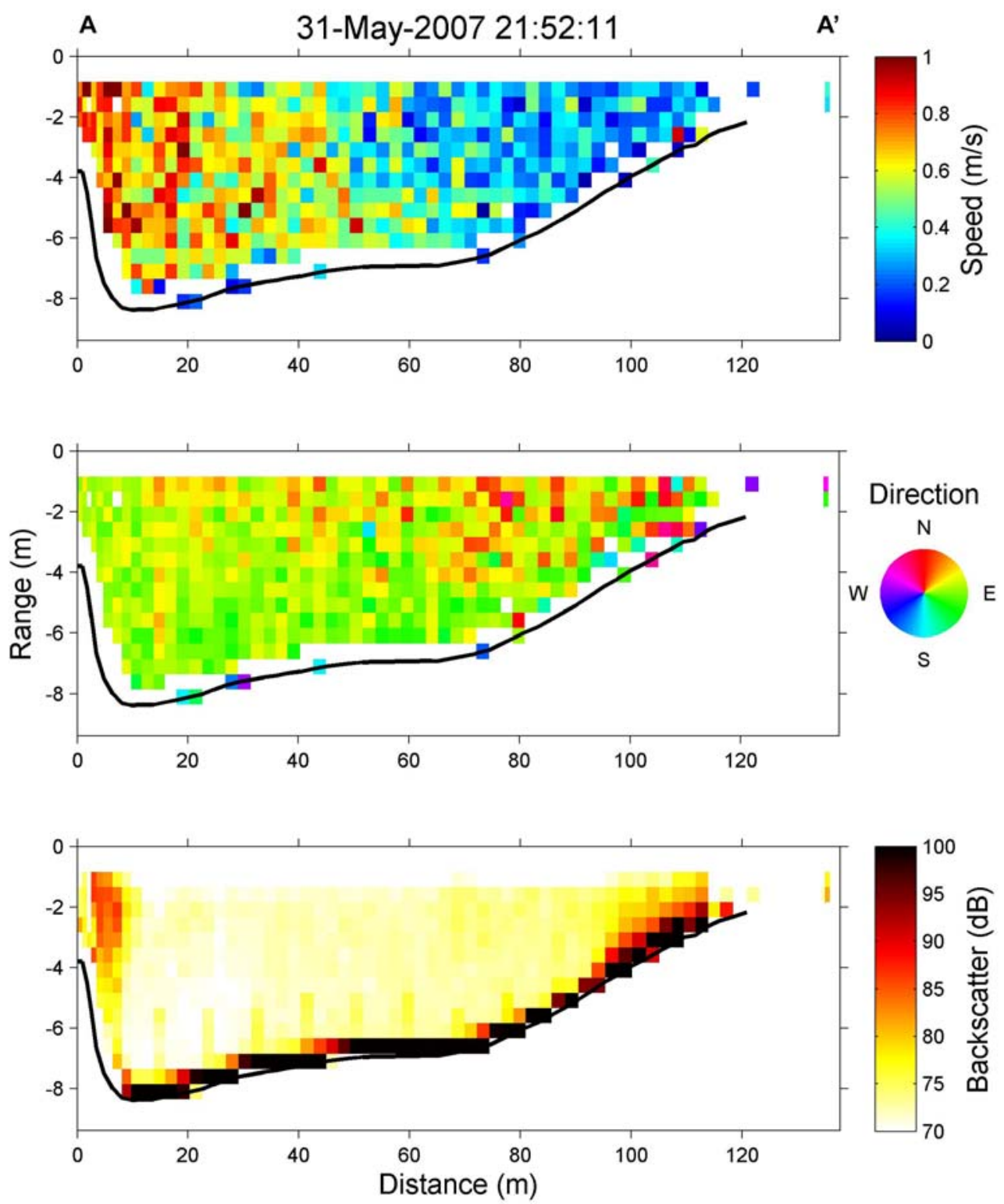

Fig. 17. Cross-sectional diagram of ADCP derived current velocity (top), current direction (middle) and measured backscatter (bottom) showing stronger current velocities along northwest edge of the entrance to Westcott Bay (left edge of top plot) Data averaged across 5 ensembles (across distance). 
Figures 18 and 19 illustrate the strong currents flowing out of the entrance of Westcott Bay under an ebbing tide of June 2, 2007. Current velocities were strongest $(0.5-0.6 \mathrm{~m} / \mathrm{s})$ in the middle of the Westcott Bay entrance and lacked the lateral asymmetry observed during flood tide (Fig. 16).

\section{2-Jun-2007 16:53:11}

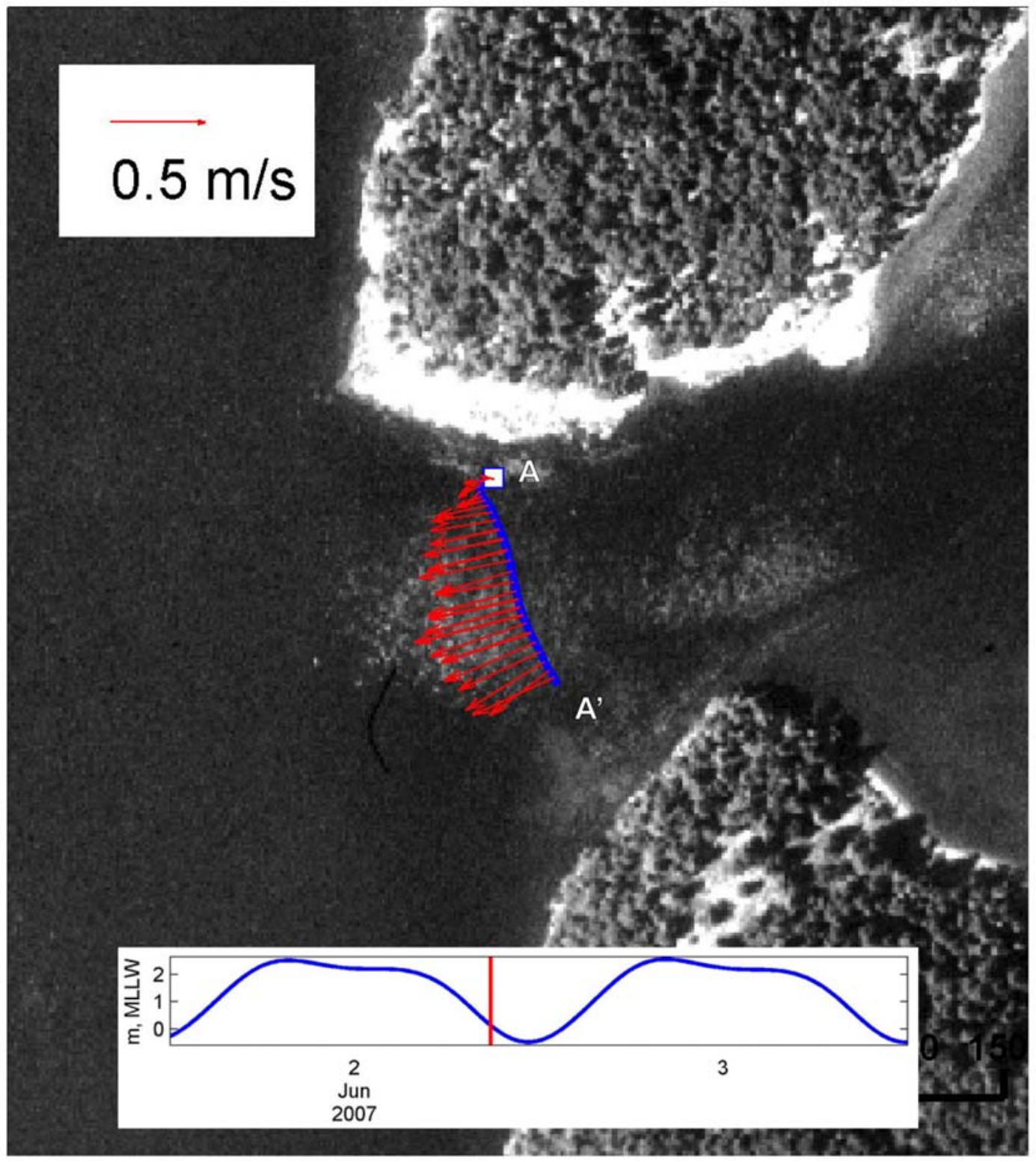

Fig. 18. Map of depth-averaged current velocity averaged across 5 ensembles (lateral distance) during ebbing tide of June 2, 2007 (inset). Current velocities were strongest in the middle of the Westcott Bay entrance and lacked the lateral asymmetry observed during flood tide. 

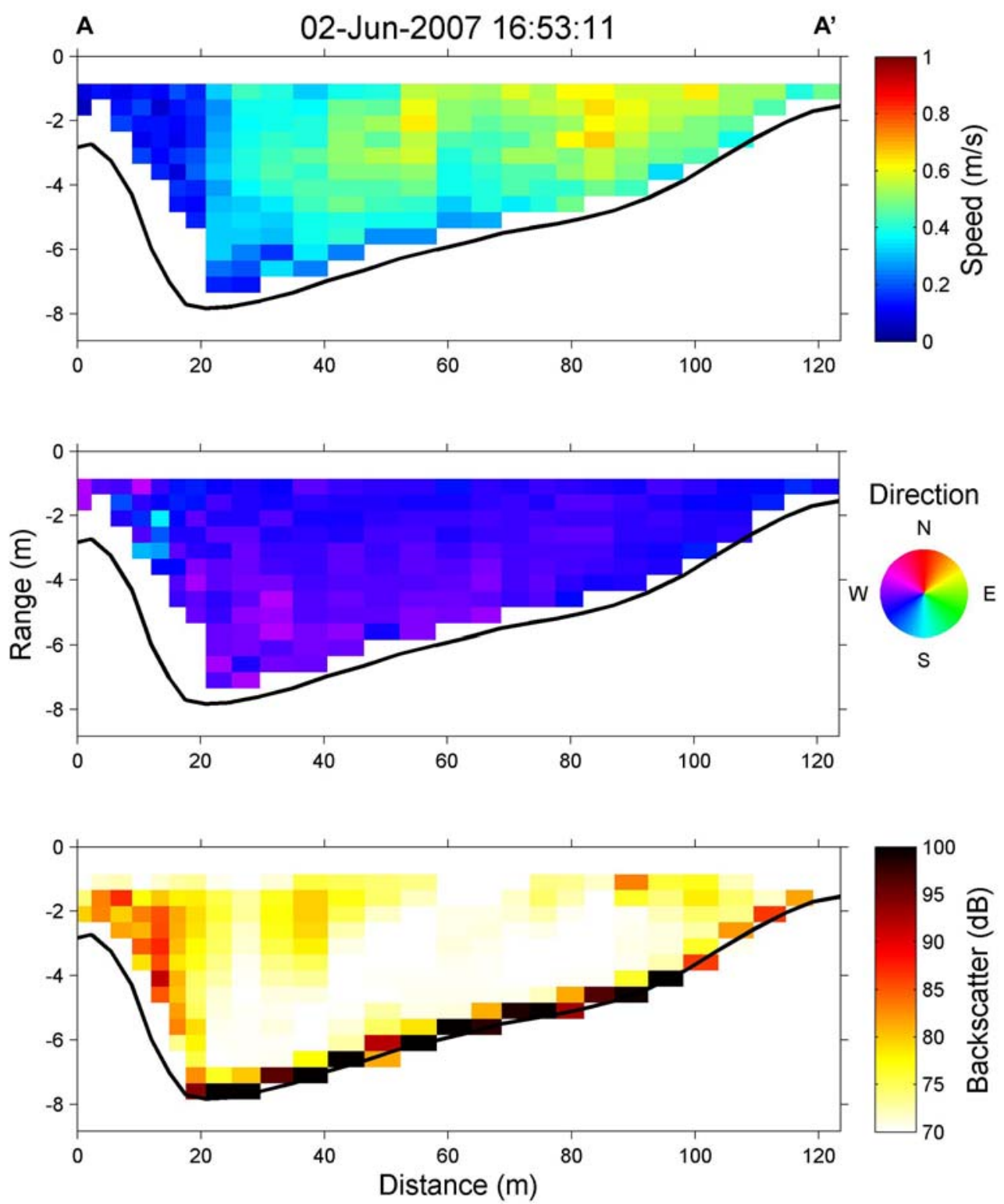

Fig. 19. Cross-sectional diagram of ADCP derived current velocity (top), current direction (middle) and measured backscatter (bottom) during an ebbing tide. Currents were stronger in the middle of the entrance to Westcott Bay and more symmetric than during flood tide. Data averaged across 5 ensembles (across distance) and are coarser than data in Figure 17 because of higher boat speed during data collection. 
Figure 20 shows the ADCP data collected on all transects of May 31, 2007 (from west to east) over the period of 2 hours as the tide flooded into Westcott Bay. Generally, higher currents were found along the central axis of Westcott Bay, and especially along the northwest edge of the entrance to Westcott Bay. A slight eddy was apparent west of Bell Point in the entrance to Garrison Bay with flow directed in a clockwise gyre. The northern portion of this eddy (black arrows) correlates with a region of poor sediment sorting (Fig. 12).

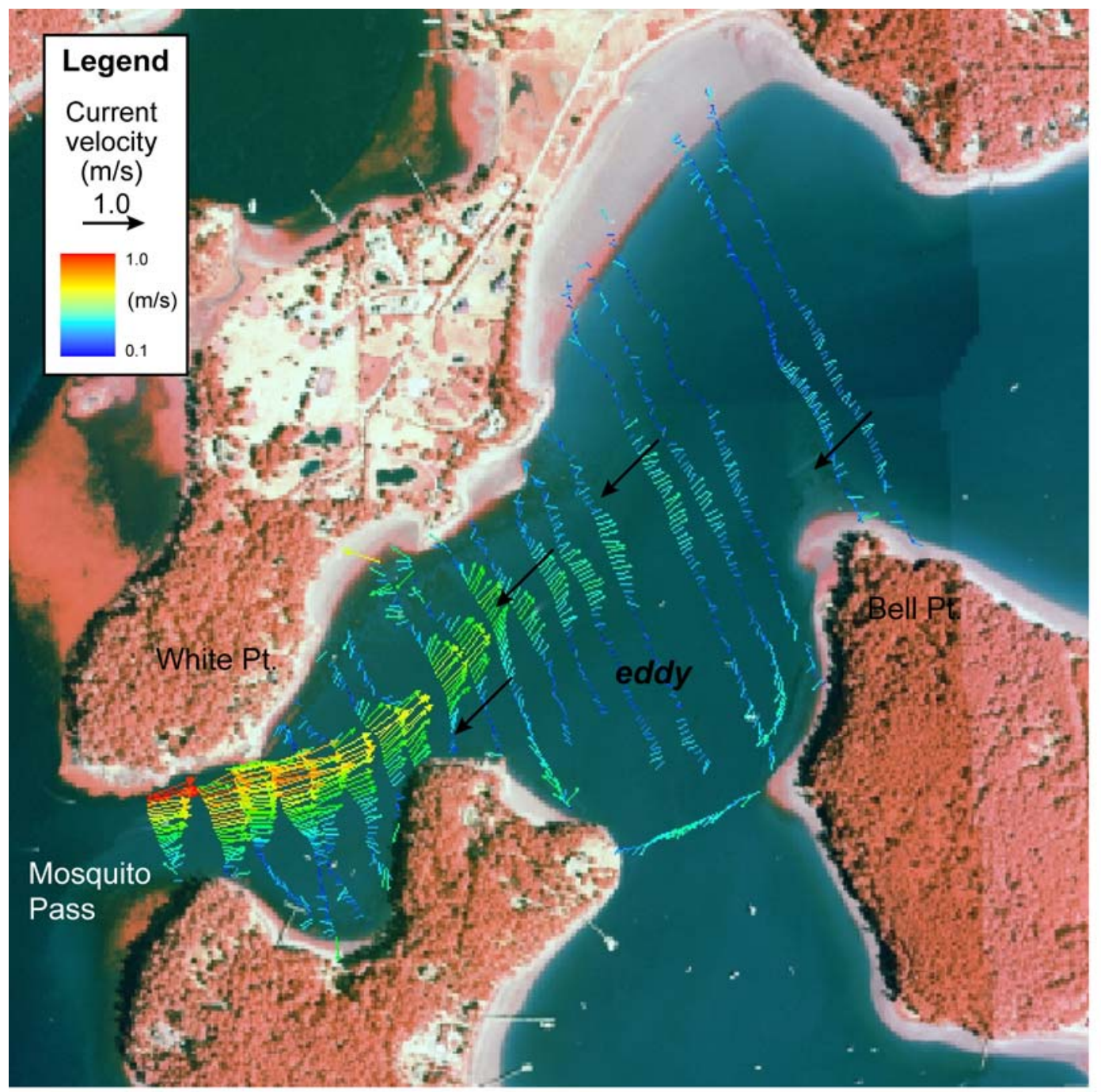

Fig. 20. Map of depth-averaged current velocities and directions over a 2- hour flood tide period on May 31, 2007 (velocities scaled to arrow in legend and color coded: red=high, blue=low). Highest velocities were observed along the northern portion of the main channel into Westcott Bay, while lower velocities occured along the edges inside the entrance and generally within the central bay. A clockwise eddy was apparent west of Bell Point within the entrance to Garrison Bay. The northern margin of the eddy (black arrows) correlates with the area of poor sorting in Figure 12. 


\section{Conclusion}

Seafloor mapping using a dual-frequency Biosonics acoustic sonar along with a boatmounted ADCP and RTK-DGPS enabled characterization of seafloor depth, morphology and nearshore circulation patterns during a range of tide regimes. Contemporaneous sampling and subsequent analysis of surface sediment grain size distributions provide quantitative data for classifying the seafloor by principal morphology and substrate types. Westcott Bay seafloor composition and morphology is complex in its western half where high-relief bedrock and extensive reaches of sand, gravel and cobble are exposed along a linear channel northeast from the entrance of Westcott Bay toward Bell Point. This complex topography and substrate is associated with strong currents that reach $1.0 \mathrm{~m} / \mathrm{s}$ and scour the bottom. Stronger currents along this deep channel indicate that the circulation is also partly controlled by the geomorphology. A sill $0.5-1.0 \mathrm{~m}$ shallower than the channel separates Westcott Bay from Mosquito Pass. The eastern half of Westcott Bay (east of Bell Point) in contrast, is broad, gently sloping and the surface sediments are dominated by high silt and clay fractions. Current velocities decreased steadily with distance into the head of the bay. In the central portion of Westcott Bay an eddy circulating in a clockwise rotation was observed during a flood tide. A portion of this eddy coincided with a region of poor sediment sorting and complex seafloor morphology. It remains uncertain if the flux, transport, and accumulation of sediment in Westcott Bay are adversely impacting Z. marina. Ongoing and future efforts will synthesize the data reported here with time series measurements of water quality to develop models of sediment transport and habitat conditions to explore environmental variability and possible thresholds of stress to eelgrass growth and recovery.

\section{Acknowledgements}

We thank Sandy Wyllie-Echeverria, Friday Harbor Laboratories, and Jim Slocomb for significant logistical support under short notice. Special thanks go to Mark Bullington of Westcott Bay Sea Farms for access and use of the sea farms for cruise operations. This work was funded by WA DNR Inter-Agency Agreement 07-324 and the U.S. Geological Survey Coastal and Marine Geology Program and the U.S. Geological Survey Multidisciplinary Studies of Coastal Habitats in Puget Sound (CHIPS) Project. 


\section{References}

Berry, H.D., A.T. Sewell, S. Wyllie-Echeverria, B.R. Reeves, T.F. Mumford, Jr., Skalski, R.C. Zimmerman, and J. Archer. 2003. Puget Sound Submerged Vegetation Monitoring Project: 2000-2002 Monitoring Report. Nearshore Habitat Program, Washington State Department of Resources. Olympia, WA. 60 p.

Friends of the San Juans, J. Slocomb, S. Buffum-Field, S. Wyllie-Echeverria, J. Norris, I. Fraser, and J. Cordell. 2004. San Juan County Eelgrass Survey Mapping Project Final Report, Friday Harbor, WA, 40.p.

Guy, H.P., 1969. Laboratory theory and methods for sediment analysis. In: Techniques of Water-Resources Investigations of the United States Geological Survey, United States Government Printing Office, Washington, DC, pp.iii-55.

Oberg K.A., Morlock, S.E., and Caldwell, W.S., 2005, Quality-assurance plan for discharge measurements using acoustic doppler current profilers: U.S. Geological Survey Scientific Investigations Report 2005-5183, 46 p. [http://pubs.usgs.gov/sir/2005/5183/SIR_2005-5183.pdf].

Wyllie-Echeverria, S., Mumford, T., Gaydos, J. and Buffum, S. 2003. Z. marina declines in San Juan County, WA. Westcott Bay Taskforce Mini-Workshop 26, July 2003. 18. p. http://mehp.vetmed.ucdavis.edu/pdfs/eelgrassrpt.pdf

\section{Revision Information}

Please refer to http://pubs.usgs.gov/of/2007/1305/ for additions and revisions to this report. 


\section{Data Catalogue}

All data generated from this mapping of bathymetry, substrate type and nearshore currents are referenced to USGS Cruise ID B-6-07-PS.

\section{Metadata}

Metadata are available at URL:

http://walrus.wr.usgs.gov/infobank/b/b607ps/html/b-6-07-ps.meta.html

\section{Digital surface elevation data}

A survey log summarizing line numbers, file names, survey information and environmental conditions are provided in Appendix 1.

Digital $\mathrm{x}, \mathrm{y}, \mathrm{z}$ (depth) data for individual survey lines are provided as text files on the data

CD under B-6-07-PS/bathymetry/line\#.xyz and for the entire survey under B-6-07-PS/bathymetry/westcott0507.xyz.

\section{Digital sediment grain size data}

Station information for the sediment grain size samples is provided in Appendix 2 and the summary grain size results are listed in Appendix 3.

\section{Digital ADCP data}

The ADCP data with current velocity, direction and backscatter amplitude are transferred to DNR on the attached data CD in three formats:

1) original WinRiver filename_T.OOO format, which can be opened with any text editor software (see B-6-07-PS/ADCP/WESTCOTT_DAY\#/filename)

- (3 folders, one for each day)

2) graphic JPG cross-sections of the RAW ADCP bottom tracked data by line (see B-6-07-PS/ADCP/WESTCOTT/ADCP_jpegs/)

3) graphic JPG cross-sections and depth averaged maps of currents averaged across 5 ensembles (horizontal averaging) by line (see B-6-07-PS/ADCP/WESTCOTT/ADCP/processedData/)

Please refer to Appendix 1 to cross reference filename with line number. 


\begin{tabular}{|c|c|c|c|c|c|c|}
\hline Line & Biosonics_Filename & Date Collected & $\begin{array}{l}\text { Elapsed } \\
\text { Time (min) }\end{array}$ & $\begin{array}{c}\text { Total } \\
\text { Length }(\mathrm{m})\end{array}$ & ADCP_Filename & Comments \\
\hline line56_1 & 20070531_192732.dt4 & 39233.47745 & 10.13 & 1385.45 & - & 4-m contour alongshore 215 to mouth \\
\hline line126 & 20070531_194740.dt4 & 39233.49144 & 3.93 & 499.19 & - & shallow reef at start; algae \\
\hline line124 & 20070531_195257.dt4 & 39233.49512 & 2.93 & 447.99 & - & veg at start; kelp mid \\
\hline line122 & 20070531_195741.dt4 & 39233.49839 & 2.09 & 233.43 & - & reef at start \\
\hline line114 & 20070531_200633.dt4 & 39233.50456 & 1.29 & 132.1 & - & - \\
\hline line112 & 20070531_200912.dt4 & 39233.50639 & 1.53 & 155.95 & - & eelgrass at start; strong current into bay \\
\hline line110 & 20070531_201133.dt4 & 39233.50802 & 1.87 & 197.82 & - & end at dock \\
\hline line108 & 20070531_201509.dt4 & 39233.51056 & 2.5 & 264.65 & - & - \\
\hline line106 & 20070531_201843.dt4 & 39233.513 & 2.5 & 316.36 & - & - \\
\hline line104 & 20070531_202313.dt4 & 39233.51613 & 1.73 & 230.74 & - & end in eelgrass \\
\hline line102 & 20070531_202613.dt4 & 39233.51821 & 2.32 & 184.11 & - & steep rock at end with algae \\
\hline line116 & 20070531_215040.dt4 & 39233.9102 & 2.29 & 137.74 & WESC053107_000 & eelgrass at end; strong current into bay \\
\hline line113 & 20070531_215450.dt4 & 39233.91308 & 2.39 & 150.83 & WESC053107_001 & eelgrass at start \\
\hline line111 & 20070531_215830.dt4 & 39233.91564 & 4.62 & 278.88 & WESC053107_002 & circumvent dock near end \\
\hline line109 & 20070531_220607.dt4 & 39233.92093 & 4.7 & 285.15 & WESC053107_003 & - \\
\hline line107 & 20070531_221224.dt4 & 39233.92528 & 3.86 & 335.26 & WESC053107_004 & $\begin{array}{l}\text { DNR Sonde at start; high backscatter near mid } \\
\text { channel }\end{array}$ \\
\hline line105 & 20070531_221812.dt4 & 39233.92931 & 3.19 & 303.98 & WESC053107_005 & eelgrass at start/end; platform at $6 \mathrm{~m}$ \\
\hline line103 & 20070531_222309.dt4 & 39233.93274 & 3.22 & 291.39 & WESC053107_006 & strong currents/backscatter mid channel \\
\hline line101 & 20070531_222923.dt4 & 39233.93709 & 2.66 & 275.26 & WESC053107_007 & - \\
\hline line98 & 20070531_223323.dt4 & 39233.93985 & 3.43 & 322.16 & WESC053107_008 & veg/resuspension? mid channel \\
\hline line96 & 20070531_223837.dt4 & 39233.94348 & 3 & 320.43 & WESC053107_009 & $\begin{array}{l}\text { rock at start; high backscatter mid; sand/rock at } \\
\text { end }\end{array}$ \\
\hline line94 & 20070531_224300.dt4 & 39233.94652 & 4.06 & 427.19 & WESC053107_010 & rock at start; high backscatter mid \\
\hline line145 & 20070531_224950.dt4 & 39233.95126 & 3.09 & 255.9 & WESC053107_011 & across Garrison Bay mouth \\
\hline line92 & 20070531_225616.dt4 & 39233.95573 & 3.22 & 361.47 & WESC053107_012 & rock at end \\
\hline line90 & 20070531_230027.dt4 & 39233.95865 & 3.59 & 364.13 & WESC053107_013 & start just offshore of rock shoal \\
\hline
\end{tabular}




\begin{tabular}{|c|c|c|c|c|c|c|}
\hline line88 & 20070531_230525.dt4 & 39233.96209 & 5.13 & 506.17 & WESC053107_014 & start mid Garrison Bay; rock at end \\
\hline line86 & 20070531_231154.dt4 & 39233.96659 & 4.45 & 550.35 & WESC053107_015 & End mid Garrison Bay \\
\hline line84 & 20070531_232300.dt4 & 39233.97431 & 6.73 & 689.43 & - & start mid Garrison Bay; turbid water visible \\
\hline line82 & 20070531_233149.dt4 & 39233.98042 & 7.33 & 802.11 & WESC053107_016 & turbid at start \\
\hline line80 & 20070531_234002.dt4 & 39233.98613 & 6.42 & 773.01 & WESC053107_017 & eelgrass at start; strong current \\
\hline line78 & 20070531_234719.dt4 & 39233.99119 & 6.69 & 790.38 & WESC053107_018 & - \\
\hline line76 & 20070531_235515.dt4 & 39233.99669 & 6.79 & 764.38 & WESC053107_019 & - \\
\hline line74 & 20070601_000446.dt4 & 39234.00331 & 4.79 & 609.06 & - & - \\
\hline line72 & 20070601_001128.dt4 & 39234.00796 & 10.09 & 663.51 & WESC053107_020 & Bell Pt.; ADCP at 2kts \\
\hline line70 & 20070601_002231.dt4 & 39234.01563 & 6.92 & 748.56 & WESC053107_021 & - \\
\hline line35 & 20070601_011712.dt4 & 39234.05362 & 9.76 & 1102.25 & - & start E side of dock; through oyster beds \\
\hline line30 & 20070601_012702.dt4 & 39234.06047 & 9.83 & 1095.63 & - & 2nd half of oysters E side \\
\hline line38 & 20070601_013911.dt4 & 39234.06889 & 8.23 & 783.01 & - & Oyster beds W side of dock \\
\hline line42 & 20070601_014748.dt4 & 39234.07487 & 8.85 & 1053.39 & - & 2nd section of oysters W side \\
\hline line4 & 20070601_030128.dt4 & 39234.12602 & 2.97 & 184.64 & - & - \\
\hline line6 & 20070601_030543.dt4 & 39234.12898 & 3.79 & 420.21 & - & - \\
\hline line8 & 20070601_031111.dt4 & 39234.13278 & 4.56 & 591.91 & - & - \\
\hline line10 & 20070601_031654.dt4 & 39234.13675 & 6.16 & 713.08 & - & poor water quality NW head of bay \\
\hline line12 & 20070601_032411.dt4 & 39234.14179 & 0.77 & 54.84 & - & - \\
\hline line14 & 20070601_033317.dt4 & 39234.14811 & 5.73 & 775.76 & - & - \\
\hline line16 & 20070601_033954.dt4 & 39234.15271 & 5.99 & 787.77 & - & $\begin{array}{l}\text { rough microtopography? mid; whispy blades near } \\
\text { end }\end{array}$ \\
\hline line18 & 20070601_034644.dt4 & 39234.15747 & 5.69 & 751.72 & - & poor WQ; floating debris/solids \\
\hline line20 & 20070601_035342.dt4 & 39234.1623 & 5.8 & 750.28 & - & - \\
\hline line22 & 20070601_040033.dt4 & 39234.16706 & 5.89 & 747.84 & - & start near DNR station; poor WQ \\
\hline line24 & 20070601_040724.dt4 & 39234.17181 & 7.5 & 805.2 & - & avoid rock at start; revetment at end \\
\hline line26_1 & 20070601_041630.dt4 & 39234.17814 & 6.76 & 780.2 & - & revetment \\
\hline line28b & 20070601_042418.dt4 & 39234.18354 & 6.3 & 819.6 & - & microtopography? 100-200 m into line? \\
\hline line1 & 20070601_175546.dt4 & 39234.74706 & 5.62 & 386.02 & WESC060107_000 & - \\
\hline line117_1 & 20070601_181300.dt4 & 39234.75921 & 2.23 & 121.99 & WESC060107_001 & - \\
\hline line68 & 20070601_181628.dt4 & 39234.76144 & 4.09 & 428.22 & - & Alongshore $\sim 2 \mathrm{~m}$ depth \\
\hline line28 & 20070601_182129.dt4 & 39234.76491 & 0.49 & 43.85 & - & alongshore \\
\hline line28a & 20070601_182843.dt4 & 39234.76993 & 3.23 & 456.97 & - & alongshore \\
\hline line68a & 20070601_183840.dt4 & 39234.77684 & 4.86 & 517.76 & - & - \\
\hline
\end{tabular}




\begin{tabular}{|c|c|c|c|c|c|c|c|}
\hline line66 & 20070601_184430.dt4 & 39234.7809 & & 4.53 & 545.71 & - & - \\
\hline line64 & 20070601_185020.dt4 & 39234.78495 & & 4.52 & 526.99 & - & - \\
\hline line62 & 20070601_185645.dt4 & 39234.78941 & & 5.36 & 558.28 & - & - \\
\hline line60 & 20070601_190253.dt4 & 39234.79367 & & 5.59 & 546.01 & WESC060107_002 & - \\
\hline line58 & 20070601_190926.dt4 & 39234.79821 & & 5.16 & 538.53 & WESC060107_003 & - \\
\hline line56 & 20070601_191526.dt4 & 39234.80238 & & 5.03 & 548.42 & WESC060107_004 & - \\
\hline line54 & 20070601_192149.dt4 & 39234.80681 & & 2.36 & 264.09 & WESC060107_005 & - \\
\hline line52 & 20070601_194548.dt4 & 39234.82347 & & 2.19 & 239.94 & - & - \\
\hline line50 & 20070601_194845.dt4 & 39234.82553 & & 1.69 & 182.88 & - & - \\
\hline line48 & 20070601_195107.dt4 & 39234.82716 & & 1.53 & 177.97 & - & - \\
\hline line46 & 20070601_195319.dt4 & 39234.8287 & & 1.55 & 184.74 & - & - \\
\hline line44 & 20070601_195531.dt4 & 39234.83022 & & 1.92 & 216.15 & - & - \\
\hline line42_1 & 20070601_195835.dt4 & 39234.83235 & & 1.93 & 214.84 & - & - \\
\hline line 40 & 20070601_200135.dt4 & 39234.83443 & & 2.8 & 292.29 & - & - \\
\hline line38a & 20070601_200607.dt4 & 39234.83759 & & 2.79 & 333.72 & - & - \\
\hline line36 & 20070601_200924.dt4 & 39234.83986 & & 2.55 & 327.44 & - & - \\
\hline line34 & 20070601_201255.dt4 & 39234.84231 & & 2.77 & 362.52 & - & - \\
\hline line32 & 20070601_201618.dt4 & 39234.84465 & & 2.79 & 329.52 & - & - \\
\hline line30a & 20070601_202008.dt4 & 39234.84733 & & 3.16 & 405.49 & - & - \\
\hline line29 & - & 39234.87569 & - & & & WESC060107_006 & - \\
\hline line7 & - & 39234.84306 & - & & & WESC060107_007 & - \\
\hline line117_1 & - & 39234.85427 & - & & & WESC060107_008 & - \\
\hline line109a & 20070601_213757.dt4 & 39234.90135 & & 3.62 & 266.08 & WESC060107_009 & - \\
\hline line120 & 20070601_214756.dt4 & 39234.90831 & & 3.77 & 144.07 & WESC060107_010 & - \\
\hline line129 & 20070601_215431.dt4 & 39234.91285 & & 8.27 & 1047.41 & - & alongshore deep section of channel \\
\hline line129a & 20070601_220256.dt4 & 39234.9187 & & 8.77 & 1101.94 & - & alongshore \\
\hline line129b & 20070601_221150.dt4 & 39234.92488 & & 6.65 & 814.84 & - & alongshore \\
\hline line127 & 20070601_222008.dt4 & 39234.93065 & & 10.3 & 1111.56 & - & alongshore \\
\hline line127b & 20070601_223034.dt4 & 39234.93789 & & 8.93 & 938.82 & - & alongshore \\
\hline line117_1 & - & 39234.51984 & - & & & WESC060107_011 & - \\
\hline line1 & - & 39234.98581 & - & & & WESC060107_012 & - \\
\hline line137 & $20070601235118 . d t 4$ & 39234.99399 & & 8.96 & 487.5 & WESC060107 013 & Garrison Bay \\
\hline line1a & $20070602000201 . d t 4$ & 39235.00154 & & 4.93 & 314.37 & - & sandlance/smelt? Eelarass \\
\hline
\end{tabular}




\begin{tabular}{|c|c|c|c|c|c|c|}
\hline line147 & 20070602_000709.dt4 & 39235.00497 & 2.93 & 297.05 & - & - \\
\hline line149 & 20070602_001132.dt4 & 39235.00802 & 4.13 & 430.32 & - & - \\
\hline line151 & 20070602_001733.dt4 & 39235.01219 & 4.03 & 491.6 & - & - \\
\hline line153 & 20070602_002252.dt4 & 39235.01588 & 5.33 & 580.7 & - & - \\
\hline line155 & 20070602_003013.dt4 & 39235.02098 & 4.56 & 589.98 & - & - \\
\hline line157 & 20070602_003610.dt4 & 39235.02513 & 4.8 & 520.42 & - & - \\
\hline line159 & 20070602_004309.dt4 & 39235.02997 & 4.07 & 480.18 & - & - \\
\hline line165 & 20070602_010202.dt4 & 39235.04309 & 2.52 & 331.02 & - & - \\
\hline line167 & 20070602_010524.dt4 & 39235.04542 & 4.99 & 715.89 & - & - \\
\hline line169 & 20070602_011120.dt4 & 39235.04955 & 6.13 & 713.93 & - & - \\
\hline line171 & 20070602_011826.dt4 & 39235.05447 & 3.06 & 359.12 & - & - \\
\hline line173 & 20070602_012254.dt4 & 39235.05757 & 2 & 236.97 & - & - \\
\hline line181 & 20070602_013347.dt4 & 39235.06513 & 3.8 & 264.35 & - & - \\
\hline line171a & 20070602_024828.dt4 & 39235.11699 & 2.26 & 258.12 & - & - \\
\hline line173a & 20070602_025142.dt4 & 39235.11922 & 2.26 & 276.34 & - & - \\
\hline line175a & 20070602_025445.dt4 & 39235.12135 & 3.33 & 348.32 & - & - \\
\hline line177a & 20070602_025834.dt4 & 39235.124 & 2.69 & 330.08 & - & - \\
\hline line179a & 20070602_030156.dt4 & 39235.12634 & 2.56 & 304.66 & - & - \\
\hline line1b & 20070602_030433.dt4 & 39235.12816 & 1.97 & 235.78 & - & - \\
\hline line181a & 20070602_030944.dt4 & 39235.13176 & 1.73 & 201.16 & - & - \\
\hline line183 & 20070602_031224.dt4 & 39235.1336 & 1.4 & 164.83 & - & - \\
\hline line184 & 20070602_031414.dt4 & 39235.13487 & 10.66 & 1491.02 & - & alongshore \\
\hline
\end{tabular}




\begin{tabular}{|c|c|c|c|c|c|c|c|}
\hline line117_1 & - & & 39235.63194 & - & - & WESC060207_004 & - \\
\hline line1 & - & & 39235.6375 & - & - & WESC060207_005 & - \\
\hline line29 & - & & 39235.64444 & - & - & WESC060207_006 & - \\
\hline line117_1 & - & & 39235.65347 & - & - & WESC060207_007 & - \\
\hline line1 & - & - & & - & - & WESC060207_008 & time in file \\
\hline line29 & - & & 39235.66944 & - & - & WESC060207_009 & - \\
\hline line117_1 & - & & 39235.67847 & - & - & WESC060207_010 & - \\
\hline line1 & - & - & & - & - & WESC060207_011 & time in file \\
\hline line29 & - & & 39235.69375 & - & - & WESC060207_012 & - \\
\hline line117_1 & - & & 39235.70347 & - & - & WESC060207_013 & - \\
\hline line68_z & 20070602 175434.dt4 & & 39235.74623 & 13.69 & 2045.87 & - & alongshore \\
\hline line73 & 20070602_181503.dt4 & & 39235.76045 & 7.16 & 554.73 & WESC060207_014 & across Mosquito Pass; boat wake; eelgrass \\
\hline line73_2 & 20070602_193824.dt4 & & 39235.81833 & 4.62 & 333.02 & WESC060207_015 & across Mosquito Pass (replicate) \\
\hline line193 & 20070602_194305.dt4 & & 39235.82159 & 10.37 & 1435.99 & - & along main axis of Westcott Bay channel \\
\hline line2 & 20070602_201318.dt4 & & 39235.84257 & 13.86 & 1430.5 & WESC060207_016 & alongshore \\
\hline line117_1 & - & & 39235.85417 & - & - & WESC060207_017 & - \\
\hline line126a & 20070602_203845.dt4 & & 39235.86024 & 4.22 & 455.88 & WESC060207_020 & - \\
\hline line123 & 20070602_204727.dt4 & & 39235.86628 & 5.27 & 341.79 & WESC060207_021 & - \\
\hline line121 & 20070602_205353.dt4 & & 39235.87074 & 2.53 & 207.56 & WESC060207_022 & boat wake \\
\hline line119_1 & 20070602_205741.dt4 & & 39235.87338 & 2.02 & 139.15 & WESC060207_023 & - \\
\hline line118 & 20070602_210119.dt4 & & 39235.87591 & 1.85 & 109.13 & WESC060207_024 & - \\
\hline line117_1 & - & - & & - & - & WESC060207_025 & - \\
\hline line99 & 20070602_211052.dt4 & & 39235.88257 & 3.49 & 209.19 & WESC060207_026 & eelgrass \\
\hline line97 & 20070602_211614.dt4 & & 39235.88632 & 4.67 & 247.86 & WESC060207_027 & eelgrass \\
\hline line95 & 20070602_212315.dt4 & & 39235.89116 & 4.65 & 262.69 & WESC060207_028 & eelgrass \\
\hline line93 & 20070602_212925.dt4 & & 39235.89544 & 8 & 450.8 & WESC060207_029 & - \\
\hline line117_1 & - & - & & - & - & WESC060207_031 & - \\
\hline line138 & 20070602_222112.dt4 & & 39235.9314 & 3.49 & 457.26 & - & - \\
\hline line140 & 20070602_222543.dt4 & & 39235.93454 & 2.99 & 408.46 & - & - \\
\hline line142 & 20070602_222930.dt4 & & 39235.93716 & 2.5 & 335.21 & - & - \\
\hline line91 & 20070602_230431.dt4 & & 39235.96148 & 2.46 & 325.6 & - & - \\
\hline line89 & 20070602_230728.dt4 & & 39235.96353 & 2.66 & 359.33 & - & - \\
\hline line87 & 20070602_231106.dt4 & & 39235.96605 & 2.59 & 348.12 & - & - \\
\hline
\end{tabular}


line85 20070602_231421.dt4

line83 20070602 231849.dt4

line81 20070602_232255.dt4

line79 20070602_232712.dt4
39235.9683

39235.97141

39235.97425

39235.97723
3.75

3.43

3.79

3.46
418.67

432.02

471.36

480.54 


\begin{tabular}{|c|c|c|c|c|c|c|}
\hline Station & Local_Time & UTC & Lon & Lat & Depth_m & Comment \\
\hline 1 & $6 / 1 / 07$ 20:44 & 6/2/07 3:44 & -123.1430877 & 48.60642247 & 2.286 & - \\
\hline 2 & 6/1/07 20:35 & 6/2/07 3:35 & -123.1416559 & 48.60596625 & 2.1336 & $18.6 \mathrm{C}$ \\
\hline 3 & $6 / 1 / 07$ 20:28 & 6/2/07 3:28 & -123.1396819 & 48.60476647 & 2.4384 & $22.4 \mathrm{C}$ \\
\hline 4 & $6 / 1 / 07$ 20:21 & 6/2/07 3:21 & -123.1383557 & 48.6034425 & 2.4384 & $21 \mathrm{C}$ \\
\hline 5 & 6/1/07 20:10 & 6/2/07 3:10 & -123.1379259 & 48.60230609 & 2.1336 & - \\
\hline 6 & 6/1/07 20:05 & 6/2/07 3:05 & -123.1403608 & 48.60044935 & 3.3528 & - \\
\hline 7 & $6 / 2 / 0716: 50$ & 6/2/07 23:50 & -123.1412818 & 48.60175168 & 3.6576 & - \\
\hline 8 & 6/2/07 17:00 & 6/3/07 0:00 & -123.1421506 & 48.60297386 & 3.6576 & $19 \mathrm{C}$ \\
\hline 9 & 6/2/07 17:05 & 6/3/07 0:05 & -123.1427175 & 48.6044497 & 3.048 & WBN-SONDE \\
\hline 10 & 6/1/07 20:48 & 6/2/07 3:48 & -123.1438967 & 48.60541356 & 3.048 & - \\
\hline 11 & $6 / 1 / 0720: 54$ & 6/2/07 3:54 & -123.1458085 & 48.60390776 & 3.3528 & - \\
\hline 12 & 6/2/07 16:27 & 6/2/07 23:27 & -123.1449813 & 48.60267691 & 3.9624 & - \\
\hline 13 & 6/2/07 16:35 & 6/2/07 23:35 & -123.1442752 & 48.60168593 & 3.9624 & - \\
\hline 14 & $6 / 2 / 0716: 45$ & 6/2/07 23:45 & -123.1434713 & 48.60059519 & 4.572 & - \\
\hline 15 & 6/1/07 19:24 & 6/2/07 2:24 & -123.1421019 & 48.59864869 & 2.4384 & - \\
\hline 16 & 6/1/07 17:10 & 6/2/07 0:10 & -123.1439795 & 48.5976315 & 2.1336 & floc? \\
\hline 17 & $6 / 2 / 0715: 40$ & 6/2/07 22:40 & -123.1449351 & 48.59896955 & 4.2672 & - \\
\hline 18 & 6/2/07 16:05 & 6/2/07 23:05 & -123.1462388 & 48.60026471 & 4.572 & - \\
\hline 19 & 6/2/07 16:09 & 6/2/07 23:09 & -123.1473201 & 48.60179786 & 3.6576 & - \\
\hline 20 & 6/2/07 16:20 & 6/2/07 23:20 & -123.148262 & 48.60313373 & 2.1336 & - \\
\hline 21 & 6/2/07 16:15 & 6/2/07 23:15 & -123.1498974 & 48.60172972 & 1.9812 & - \\
\hline 22 & $6 / 2 / 07$ 15:20 & $6 / 2 / 0722: 20$ & -123.1492409 & 48.59979738 & 2.4384 & - \\
\hline 23 & $6 / 2 / 0715: 30$ & 6/2/07 22:30 & -123.1484785 & 48.59869397 & 5.0292 & - \\
\hline 24 & 6/2/07 15:35 & 6/2/07 22:35 & -123.1476722 & 48.59758652 & 5.1816 & - \\
\hline 25 & 6/1/07 17:00 & 6/2/07 0:00 & -123.1467698 & 48.59627812 & 2.286 & - \\
\hline 26 & 6/1/07 16:45 & 6/1/07 23:45 & -123.1480227 & 48.59330183 & 2.1336 & - \\
\hline 27 & 6/1/07 16:55 & 6/1/07 23:55 & -123.1490594 & 48.59477483 & 4.4196 & - \\
\hline 28 & 6/2/07 15:05 & 6/2/07 22:05 & -123.1505265 & 48.59684596 & 5.1816 & mud \\
\hline 29 & 6/2/07 15:15 & 6/2/07 22:15 & -123.1516348 & 48.59839777 & 1.6764 & - \\
\hline 30 & $6 / 2 / 0714: 28$ & 6/2/07 21:28 & -123.1554968 & 48.59805066 & 1.0668 & - \\
\hline 31 & 6/2/07 14:35 & 6/2/07 21:35 & -123.1541046 & 48.59609766 & 5.1816 & - \\
\hline
\end{tabular}




\begin{tabular}{|c|c|c|c|c|c|}
\hline 6/1/07 16:40 & 6/1/07 23:40 & -123.1527509 & 48.59414851 & 3.9624 & - \\
\hline 6/1/07 16:35 & 6/1/07 23:35 & -123.1517106 & 48.59270764 & 1.2192 & - \\
\hline 6/1/07 16:27 & 6/1/07 23:27 & -123.1567103 & 48.5939465 & 1.8288 & - \\
\hline 6/1/07 16:20 & 6/1/07 23:20 & -123.1575561 & 48.59512673 & 3.5052 & - \\
\hline 6/1/07 16:14 & 6/1/07 23:14 & -123.1581907 & 48.59599792 & 7.0104 & - \\
\hline 6/1/07 15:30 & 6/1/07 22:30 & -123.1589914 & 48.59715466 & 3.9624 & - \\
\hline 6/1/07 15:18 & 6/1/07 22:18 & -123.1599242 & 48.59843233 & 1.524 & - \\
\hline 6/1/07 15:10 & 6/1/07 22:10 & -123.1619828 & 48.59606753 & 1.2192 & - \\
\hline 6/1/07 15:00 & 6/1/07 22:00 & -123.1610457 & 48.59478295 & 5.7912 & - \\
\hline 6/1/07 14:55 & 6/1/07 21:55 & -123.1601357 & 48.5934547 & 8.5344 & - \\
\hline 6/1/07 14:40 & 6/1/07 21:40 & -123.1593413 & 48.59231698 & 5.7912 & - \\
\hline 6/1/07 14:34 & 6/1/07 21:34 & -123.1581413 & 48.59064567 & 1.8288 & water temp $65 \mathrm{~F}$ \\
\hline 6/1/07 14:28 & $6 / 1 / 0721: 28$ & -123.1595903 & 48.5902156 & 5.1816 & - \\
\hline 6/1/07 14:15 & 6/1/07 21:15 & -123.1611018 & 48.5898281 & 2.1336 & - \\
\hline 6/1/07 14:05 & 6/1/07 21:05 & -123.1588285 & 48.58774659 & 3.048 & - \\
\hline 6/1/07 13:50 & 6/1/07 20:50 & -123.1640143 & 48.59094643 & 1.524 & eelgrass dense \\
\hline 6/1/07 13:40 & 6/1/07 20:40 & -123.1645209 & 48.59171271 & 7.62 & cobble \\
\hline 6/1/07 13:35 & $6 / 1 / 0720: 35$ & -123.1649866 & 48.59240379 & 1.8288 & fish \\
\hline 6/1/07 13:32 & $6 / 1 / 0720: 32$ & -123.1656586 & 48.59335283 & 0.762 & patchy eelgrass \\
\hline 6/1/07 13:08 & 6/1/07 20:08 & -123.1675292 & 48.591132 & 1.0668 & eelgrass near DNR site \\
\hline 6/1/07 13:00 & $6 / 1 / 0720: 00$ & -123.1668798 & 48.59026557 & 6.096 & sandy \\
\hline $6 / 1 / 0712: 57$ & 6/1/07 19:57 & -123.1663797 & 48.58958473 & 1.8288 & - \\
\hline 6/1/07 12:50 & 6/1/07 19:50 & -123.1657538 & 48.58869312 & 0.9144 & - \\
\hline 6/1/07 12:40 & 6/1/07 19:40 & -123.170589 & 48.59020657 & 5.7912 & rock, no sample \\
\hline 6/1/07 12:25 & 6/1/07 19:25 & -123.1702311 & 48.58971595 & 6.096 & sand cobble \\
\hline 6/1/07 12:15 & 6/1/07 19:15 & -123.1698061 & 48.58911829 & 0.9144 & eelgrass \\
\hline 6/1/07 12:05 & 6/1/07 19:05 & -123.1704144 & 48.5884425 & 0.4572 & sand, cobble, eelgrass \\
\hline 6/1/07 23:55 & 6/2/07 6:55 & -123.171477 & 48.5888478 & 1.9812 & Rocky, eelgrass (drops=3) \\
\hline 6/1/07 11:35 & 6/1/07 21:35 & -123.1729 & 48.58919782 & 8.5344 & Mosquito Pass \\
\hline $6 / 2 / 0713: 28$ & $6 / 2 / 0720: 28$ & -123.1425453 & 48.6053862 & 0.3048 & WBN-1 \\
\hline $6 / 2 / 0713: 28$ & $6 / 2 / 0720: 28$ & -123.1425453 & 48.6053862 & 0.3048 & WBN-2 \\
\hline 6/2/07 13:28 & $6 / 2 / 0720: 28$ & -123.1425453 & 48.6053862 & 0.3048 & WBN-3 \\
\hline 6/2/07 13:59 & $6 / 2 / 0720: 59$ & -123.1576585 & 48.5934125 & 0.4572 & BP-1 \\
\hline
\end{tabular}




$\begin{array}{lllllll}65 & 6 / 2 / 0713: 59 & 6 / 2 / 0720: 59 & -123.1576585 & 48.5934125 & 0.4572 & \text { BP-2 } \\ 66 & 6 / 2 / 0713: 59 & 6 / 2 / 0720: 59 & -123.1576585 & 48.5934125 & 0.4572 & \text { BP-3 } \\ 67 & 6 / 2 / 0714: 12 & 6 / 2 / 0721: 12 & -123.1674891 & 48.5911956 & 1.524 & \text { WP-SONDE } \\ 68 & 6 / 2 / 0714: 19 & 6 / 2 / 0721: 19 & -123.1578369 & 48.5933055 & 2.5908 & \text { BP-SONDE } \\ 69 & 6 / 2 / 0714: 47 & 6 / 2 / 0721: 47 & -123.1421332 & 48.5996015 & 1.3716 & \text { WBS-SONDE } \\ 70 & 6 / 2 / 0714: 52 & 6 / 2 / 0721: 52 & -123.141445 & 48.5995073 & 0.9144 & \text { WBS } \\ 71 & 6 / 1 / 0710: 00 & 6 / 1 / 0717: 00 & -123.145544 & 48.597332 & 2.4384 & \text { SF_Dock } \\ 72 & 6 / 2 / 0713: 28 & 6 / 2 / 0720: 28 & -123.1425453 & 48.6053862 & 0.3048 & \text { WBN-PUSH } \\ 73 & 6 / 2 / 0713: 59 & 6 / 2 / 0720: 59 & -123.1576585 & 48.5934125 & 0.4572 & \text { BP-PUSH }\end{array}$

NOTES: Depth=depth in meters at time of sampling (not corrected to a datum).

Triplicates taken at WBN and BP.

PUSH=Pushcore 6 inch. 
APPENDIX III. Grain size results. Size classes in percent.

\begin{tabular}{|c|c|c|c|c|c|c|c|c|c|c|c|c|}
\hline Station & Boulder & Cobble & Gravel & Sand & Silt & Clay & Mud & $\begin{array}{c}\text { Mean } \\
\text { Phi }\end{array}$ & $\begin{array}{c}\text { Mean } \\
\mathrm{mm}\end{array}$ & Std_Dev & Skewness & Kurtosis \\
\hline 1 & 0 & 0 & 0.46 & 80.41 & 15.96 & 3.17 & 19.13 & 3.552 & 0.085 & 1.482 & 2.246 & 10.021 \\
\hline 2 & 0 & 0 & 0 & 61.11 & 31.68 & 7.21 & 38.89 & 4.174 & 0.055 & 2.011 & 1.306 & 4.317 \\
\hline 3 & 0 & 0 & 0.6 & 61.16 & 28.84 & 9.4 & 38.25 & 4.102 & 0.058 & 2.354 & 0.975 & 3.356 \\
\hline 4 & 0 & 0 & 3.11 & 87.59 & 6.85 & 2.44 & 9.29 & 2.588 & 0.166 & 1.673 & 1.847 & 9.374 \\
\hline 5 & 0 & 0 & 0 & 90.17 & 7.16 & 2.67 & 9.83 & 3.015 & 0.124 & 1.473 & 2.733 & 11.841 \\
\hline 6 & 0 & 0 & 0 & 45.37 & 45.31 & 9.32 & 54.63 & 4.731 & 0.038 & 2.112 & 0.866 & 3.148 \\
\hline 7 & 0 & 0 & 0 & 7.02 & 75.28 & 17.7 & 92.98 & 6.207 & 0.014 & 1.816 & 0.651 & 2.778 \\
\hline 8 & 0 & 0 & 0 & 5.82 & 75.34 & 18.84 & 94.18 & 6.34 & 0.012 & 1.799 & 0.607 & 2.689 \\
\hline 9 & 0 & 0 & 0 & 6.08 & 72.56 & 21.37 & 93.92 & 6.486 & 0.011 & 1.888 & 0.264 & 2.915 \\
\hline 10 & 0 & 0 & 0 & 59.01 & 34.67 & 6.32 & 40.99 & 4.292 & 0.051 & 1.86 & 1.414 & 4.69 \\
\hline 11 & 0 & 0 & 0 & 10.14 & 74.02 & 15.84 & 89.86 & 6.019 & 0.015 & 1.826 & 0.75 & 2.937 \\
\hline 12 & 0 & 0 & 0 & 5.85 & 73.9 & 20.25 & 94.15 & 6.391 & 0.012 & 1.856 & 0.443 & 2.767 \\
\hline 13 & 0 & 0 & 0 & 8.19 & 73.86 & 17.94 & 91.81 & 6.185 & 0.014 & 1.839 & 0.675 & 2.708 \\
\hline 14 & 0 & 0 & 0 & 6.78 & 75.13 & 18.09 & 93.22 & 6.216 & 0.013 & 1.831 & 0.671 & 2.73 \\
\hline 15 & 0 & 0 & 0.94 & 49.29 & 35.59 & 14.18 & 49.77 & 4.644 & 0.04 & 2.672 & 0.487 & 2.26 \\
\hline 16 & 0 & 0 & 0.49 & 81.68 & 12.86 & 4.98 & 17.84 & 3.024 & 0.123 & 2.047 & 1.84 & 6.068 \\
\hline 17 & 0 & 0 & 0.39 & 14.25 & 66.93 & 18.42 & 85.36 & 6.053 & 0.015 & 2.025 & 0.328 & 2.946 \\
\hline 18 & 0 & 0 & 0 & 11.37 & 74.86 & 13.77 & 88.63 & 5.832 & 0.018 & 1.774 & 0.953 & 3.269 \\
\hline 19 & 0 & 0 & 0 & 6.29 & 76.13 & 17.59 & 93.71 & 6.226 & 0.013 & 1.807 & 0.596 & 2.945 \\
\hline 20 & 0 & 0 & 0 & 13.6 & 75.04 & 11.37 & 86.4 & 5.637 & 0.02 & 1.728 & 1.048 & 3.733 \\
\hline 21 & 0 & 0 & 0 & 75.91 & 19.13 & 4.96 & 24.09 & 3.307 & 0.101 & 2.043 & 1.624 & 5.127 \\
\hline 22 & 0 & 0 & 0 & 20.47 & 66.11 & 13.42 & 79.53 & 5.627 & 0.02 & 1.965 & 0.632 & 2.963 \\
\hline 23 & 0 & 0 & 0.23 & 16.12 & 72.3 & 11.35 & 83.65 & 5.546 & 0.021 & 1.789 & 0.902 & 3.954 \\
\hline 24 & 0 & 0 & 0 & 25.32 & 64.51 & 10.16 & 74.68 & 5.288 & 0.026 & 1.797 & 1.162 & 3.891 \\
\hline 25 & 0 & 0 & 0 & 56.15 & 34.26 & 9.59 & 43.85 & 4.311 & 0.05 & 2.319 & 0.961 & 2.98 \\
\hline 26 & 0 & 0 & 1.86 & 73.81 & 19.21 & 5.12 & 24.33 & 3.44 & 0.092 & 2.065 & 1.343 & 5.08 \\
\hline 27 & 0 & 0 & 0 & 22.68 & 64.09 & 13.23 & 77.32 & 5.556 & 0.021 & 1.977 & 0.7 & 3.052 \\
\hline 28 & 0 & 0 & 0 & 31.3 & 59.35 & 9.35 & 68.7 & 5.129 & 0.029 & 1.788 & 1.258 & 4.16 \\
\hline 29 & 0 & 0 & 0.07 & 73.92 & 20.54 & 5.48 & 26.02 & 3.383 & 0.096 & 2.145 & 1.393 & 4.508 \\
\hline
\end{tabular}




\begin{tabular}{|c|c|c|c|c|c|c|c|c|c|c|c|c|}
\hline 30 & 0 & 0 & 0.07 & 70.95 & 22.17 & 6.81 & 28.99 & 3.504 & 0.088 & 2.273 & 1.3 & 4.014 \\
\hline 31 & 0 & 0 & 0 & 37.33 & 53.64 & 9.03 & 62.67 & 5.005 & 0.031 & 1.798 & 1.355 & 4.274 \\
\hline 32 & 0 & 0 & 0 & 45.66 & 46.63 & 7.71 & 54.34 & 4.548 & 0.043 & 2.054 & 0.861 & 3.5 \\
\hline 33 & 0 & 0 & 5.83 & 71.86 & 16.62 & 5.69 & 22.31 & 3.235 & 0.106 & 2.264 & 1.069 & 4.732 \\
\hline 34 & 0 & 0 & 0 & 60.23 & 27.5 & 12.27 & 39.77 & 4.142 & 0.057 & 2.65 & 0.856 & 2.554 \\
\hline 35 & 0 & 0 & 4.83 & 81.73 & 9.44 & 3.99 & 13.43 & 2.516 & 0.175 & 2.04 & 1.734 & 6.928 \\
\hline 36 & 0 & 0 & 0 & 56.26 & 35.43 & 8.31 & 43.74 & 4.426 & 0.047 & 2.037 & 1.214 & 3.83 \\
\hline 37 & 0 & 0 & 0.09 & 59.17 & 32.8 & 7.93 & 40.73 & 4.27 & 0.052 & 2.069 & 1.241 & 3.997 \\
\hline 38 & 0 & 0 & 0 & 83.21 & 12.6 & 4.19 & 16.79 & 3.415 & 0.094 & 1.724 & 2.154 & 7.729 \\
\hline 39 & 0 & 0 & 0 & 78.16 & 15.93 & 5.91 & 21.84 & 3.599 & 0.083 & 1.937 & 1.866 & 6.029 \\
\hline 40 & 0 & 0 & 0 & 57.11 & 31.54 & 11.35 & 42.89 & 4.23 & 0.053 & 2.532 & 0.85 & 2.695 \\
\hline 41 & 0 & 0 & 0 & 82.7 & 13.58 & 3.72 & 17.3 & 3.393 & 0.095 & 1.63 & 2.318 & 8.568 \\
\hline 42 & 0 & 0 & 0 & 68.39 & 26.83 & 4.78 & 31.61 & 4.047 & 0.06 & 1.615 & 1.989 & 7.181 \\
\hline 43 & 0 & 0 & 0.05 & 83.08 & 12.88 & 3.99 & 16.87 & 3.237 & 0.106 & 1.776 & 1.989 & 7.358 \\
\hline 44 & 0 & 0 & 0 & 48.26 & 44.07 & 7.67 & 51.74 & 4.676 & 0.039 & 1.798 & 1.477 & 4.769 \\
\hline 45 & 0 & 0 & 64.34 & 26.01 & 7.59 & 2.07 & 9.66 & 0.153 & 0.9 & 2.357 & 2.247 & 7.7 \\
\hline 46 & 0 & 0 & 0 & 28.4 & 63.26 & 8.34 & 71.6 & 5.085 & 0.029 & 1.701 & 1.405 & 4.733 \\
\hline 47 & 0 & 0 & 10 & 70.51 & 14.45 & 5.04 & 19.49 & 2.732 & 0.151 & 2.404 & 0.978 & 4.434 \\
\hline 49 & 0 & 0 & 0 & 68.63 & 24 & 7.37 & 31.37 & 3.873 & 0.068 & 2.133 & 1.409 & 4.218 \\
\hline 50 & 0 & 0 & 0 & 77.45 & 16.7 & 5.84 & 22.55 & 3.345 & 0.098 & 2.102 & 1.581 & 5.143 \\
\hline 51 & 0 & 0 & 0.51 & 71.69 & 19.64 & 8.17 & 27.8 & 3.601 & 0.082 & 2.334 & 1.315 & 3.996 \\
\hline 52 & 0 & 0 & 5.57 & 90.39 & 2.82 & 1.22 & 4.04 & 2.001 & 0.25 & 1.401 & 1.837 & 13.66 \\
\hline 53 & 0 & 0 & 0 & 43.83 & 47.12 & 9.05 & 56.17 & 4.852 & 0.035 & 1.841 & 1.363 & 4.26 \\
\hline 54 & 0 & 0 & 0 & 73.72 & 21.7 & 4.58 & 26.28 & 3.479 & 0.09 & 1.903 & 1.515 & 5.539 \\
\hline 56 & 0 & 0 & 9.46 & 84.86 & 3.95 & 1.73 & 5.67 & 2.129 & 0.229 & 1.619 & 1.382 & 10.384 \\
\hline 57 & 0 & 0 & 21.69 & 73.62 & 3.47 & 1.22 & 4.69 & 1.067 & 0.477 & 1.84 & 1.529 & 7.735 \\
\hline 58 & 0 & 0 & 43.39 & 42.38 & 10.05 & 4.17 & 14.23 & 1.407 & 0.377 & 2.846 & 1.113 & 3.762 \\
\hline 59 & 0 & 0 & 0.6 & 97.52 & 1.31 & 0.57 & 1.88 & 1.912 & 0.266 & 0.909 & 4.175 & 35.176 \\
\hline 60 & 0 & 0 & 41.8 & 51.4 & 4.69 & 2.11 & 6.8 & 1.104 & 0.465 & 2.329 & 1.164 & 5.014 \\
\hline 61 & 0 & 0 & 0.95 & 56.72 & 35.26 & 7.06 & 42.32 & 4.282 & 0.051 & 2.03 & 1.031 & 4.249 \\
\hline 62 & 0 & 0 & 0 & 40.16 & 48.98 & 10.86 & 59.84 & 5.019 & 0.031 & 2.06 & 0.924 & 3.142 \\
\hline 63 & 0 & 0 & 0 & 52.8 & 39.54 & 7.66 & 47.2 & 4.489 & 0.045 & 1.977 & 1.167 & 3.915 \\
\hline
\end{tabular}




\begin{tabular}{|r|r|r|r|r|r|r|r|r|r|r|r|r|}
64 & 0 & 0 & 0.12 & 86.21 & 9.86 & 3.81 & 13.67 & 3.262 & 0.104 & 1.623 & 2.553 & 9.711 \\
\hline 65 & 0 & 0 & 0 & 90.18 & 7.22 & 2.6 & 9.82 & 3.043 & 0.121 & 1.392 & 3.172 & 13.942 \\
\hline 66 & 0 & 0 & 0.88 & 90.82 & 6.06 & 2.24 & 8.3 & 2.984 & 0.126 & 1.356 & 2.796 & 14.549 \\
\hline 67 & 0 & 0 & 1.33 & 66.3 & 22.94 & 9.43 & 32.37 & 3.684 & 0.078 & 2.551 & 1.019 & 3.223 \\
\hline 68 & 0 & 0 & 0 & 75.03 & 20.02 & 4.94 & 24.97 & 3.886 & 0.068 & 1.654 & 2.142 & 7.432 \\
\hline 69 & 0 & 0 & 0 & 9.18 & 71.74 & 19.08 & 90.82 & 6.268 & 0.013 & 1.907 & 0.412 & 2.689 \\
\hline 70 & 0 & 0 & 1.07 & 72.42 & 19.21 & 7.3 & 26.51 & 3.523 & 0.087 & 2.339 & 1.203 & 3.975 \\
\hline 71 & 0 & 0 & 7.42 & 23.29 & 52.75 & 16.54 & 69.29 & 5.161 & 0.028 & 2.851 & -0.363 & 2.892 \\
\hline
\end{tabular}

